\title{
Multi-input rectifier stage for a system of hybrid PV/wind driven PMSG
}

\author{
Shazly A. Mohamed ${ }^{1}$
}

Received: 1 August 2019 / Accepted: 2 November 2019 / Published online: 8 November 2019

(c) Springer Nature Switzerland AG 2019

\begin{abstract}
This article depicts a novel configuration of the multi-input rectifier stage for a system of hybrid PV/wind driven permanent magnet synchronous generator (PMSG). Maximum power point tracking (MPPT) techniques are applied to extract maximum power from the wind turbine and the solar module when it is obtainable to increase the PV efficiency and wind driven PMSG. Using dc/dc converter topology individually with control of MPPT to produce power. Perturb and Observe (P\&O) MPPT algorithm is applied for PV device that the dc voltage is utilized as perturbation variable whereas, in wind system, the perturbation variable is utilized in modified P\&O MPPT algorithm. In this work, the main contribution is the implementation of a PV/wind driven PMSG hybrid model in the form of Matlab Simulink based on multi-input rectifier stage. In this study, a multi-input rectifier topology for grid-inserted PV/Wind driven PMSG model has been applied. MPPT based control of PV supply is carrying out on cuk converter topology. The multi-input rectifier stage has the ability to eradicate current harmonics. Therefore, no extra input filters are required. Matlab/Simulink program is applied in the present study to implement the modeling and analysis of grid-inserted PV/wind driven PMSG based on multi-input rectifier topology.
\end{abstract}

Keywords Hybrid renewable energy system (HRES) · Wind driven PMSG system · PV system · MPPT control techniques . Multi-input rectifier topology

\section{Introduction}

The expression hybrid renewable energy is applied to depict any energy system with more than one form of generator ordinarily a traditional generator powered by diesel and renewable energy sources like photovoltaic, wind energy and hybrid system [1, 2]. Hybrid energy system is to give an economical and sustainable energy for the rustic electrification which uses a collection of non-renewable energy resources such as fossil fuel, nuclear power or a collection of renewable energy resources such as PV and wind [3]. This is clean energy and obtainable in nature. The merits above non-renewable fossil fuel based on power generation, like low contamination and high efficiency [4]. Solar system is one of the ersatz clean energy resources that are paid close interest by humans because, it is very significant to have an effective and suitable MPPT technique for the PV device [5]. There are several types of converter topology, between them we have chosen the most appropriate type which is boost-converter topology for our design, because it is widespread no isolated converter, its ability of increasing the voltage where it is also popular to have low speed wind and the impedance connected to the generator in our case need to be reduced to have it equal to the internal impedance in the generator. Occasionally this type is known the step-up converter [6]. The wind power at most depends upon geographical features and climate conditions and change occasionally. Thence, it is needful to build a system that can produce maximum power for all working conditions. Lately, PMSG is applied for wind generating system because of its merits like best reliability, low maintenance and more efficient etc. For

Shazly A. Mohamed, Eng_shazlyabdo@yahoo.com | ${ }^{1}$ Department of Electrical Engineering, Faculty of Engineering, South Valley University, Qena, Egypt. 
maximum power transfer in each wind speeds, the converter should be able to decrease PMSG terminal voltage in low speeds and raises it in high wind speeds. Numerous hybrid PV/Wind power systems with control of MPPT technique have been suggested previously $[7,8]$. In the present article, a multi-input rectifier stage for grid inserted hybrid PV/Wind driven PMSG system has been applied. Control of MPPT for the PV source is carrying out on cuk converter. The multi-input rectifier converters have the ability to cancel the high current harmonics. Therefore, no extra input filters are required. Fusion of multi-input rectifier topology works completely for individual and simultaneous operation. MPPT can be addressed by several ways, for example: $\mathrm{P} \& \mathrm{O}$, constant voltage (CV) and incremental conductance (INC) etc. It is widely applied, mostly for low-cost applications [9]. These days, utilization of solar energy includes use of PV cells, solar thermal power and solar water heating. In general, the PV device consists of PV generator which is a collection of series-shunt electrically attached solar panels. There are two techniques of our study, with and without tracking systems. The present article aims to investigate the performance of PV-wind driven PMSG hybrid energy system under various weather conditions based on multi-input rectifier topology.

The rest of the present article is arranged as follows after introduction: In Sect. 2, modeling analysis of PV system configuration is discussed. In Sect. 3, modeling analysis of wind energy conversion system (WECS) and its control strategy are presented. The proposed PV-Wind driven PMSG hybrid energy system and its components are illustrated in Sect. 4. The simulation results about the performance of hybrid model are included in Sect. 5. In Sect. 6, summary of findings is addressed.

\section{Modeling analysis of (PV) system configuration}

PV systems have two master problems which the conversion efficiency generation is very low mostly at lower irradiation status and the amount of power produced by solar modules varies incessantly with climate status. The need for MPPT, furthermore, the I-V characteristic of PV is nonlinear and generally, there is a dot on the P-V or I-V curves, known the MPP at which PV works with maximum efficiency and created its maximum power. Hence a particular photovoltaic panel composes of different PV-cells in series or shunt connections where the series connections are accountable for increasing the output voltage while, the shunt connection is accountable for increasing the current. Commonly, a number of PV modules are coordinated in series or shunt to face the energy requirements [10]. The solar cell equivalent circuit is illustrated in Fig. 1.

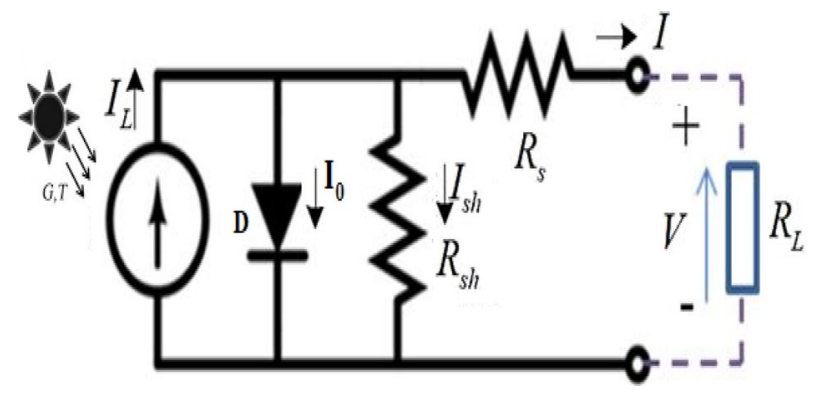

Fig. 1 Simplified electrical circuit for single diode of solar cell

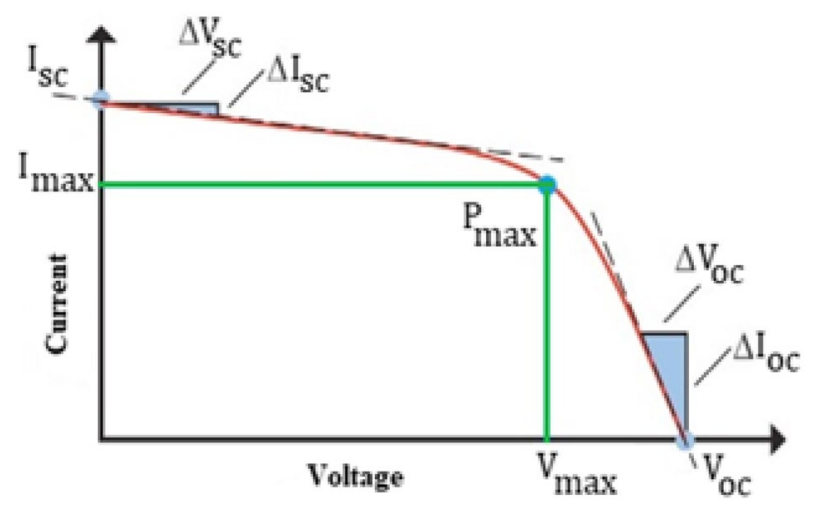

Fig. 2 Standard I-V characteristic for solar cell

Without load condition, generated current shorts through diode and with loaded condition, generated current flows through load connected and very little amount flows through diode. From the simplified circuit it is obvious that, the output current created by the solar cell is equal to that generated by the source current, minus that which flows across the diode, minus that which flows across the shunt resistor as indicated in equation below $[11,12]$.

$I=I_{L}-I_{0}-I_{\text {sh }}$

Figure 2 depicted the standard solar cell current-voltage (I-V) characteristic. The distinctive equation of a solar panel that connects solar cell parameters to the output voltage and current is derived as follows:

$I=I_{L}-I_{0}\left(\exp \left[\frac{q\left(V+I R_{s}\right)}{m k T}\right]-1\right)-\frac{\left(V+I R_{s}\right)}{R_{s h}}$

Usually, the shunt resistance $\left(R_{\text {sh }}\right)$ is very high, series resistance $\left(R_{s}\right)$ is very low and enough to neglect the two terms to simplify the characteristic equation of the solar cell model to become:

$I=I_{L}-I_{0}\left(\exp \left[\frac{q V}{m k T}\right]-1\right)$ 
where I: Represent the output current of a solar cell, V: Represent the output terminal voltage of a solar cell, $\mathrm{I}_{\mathrm{L}}$ : Light-generated current under a given insolation, $\mathrm{I}_{0}$ : Diode saturation current and $\mathrm{I}_{\mathrm{sh}}$ : Shunt current, $\mathrm{V}_{\mathrm{D}}$ : Voltage across the diode, q: Electron Charge $\left(1.60217 \times 10^{-19} \mathrm{C}\right)$ and $\mathrm{k}$ : Boltzmann Constant $\left(1.3807 \times 10^{-23} \mathrm{~J} / \mathrm{K}\right)$, m: Dimensionless ideality factor of the diode, STC: Standard test condition, $\mathrm{T}$ : Cell temperature $(\mathrm{K}), \mathrm{R}_{\mathrm{s}}$ : Series resistance of the cell $(\Omega)$ and $R_{\text {sh }}$ : Shunt resistance of the cell $(\Omega)$.

The modeling of solar energy system used in the simulation is depicted in Fig. 3. It contains a modeled PV array and converter topology controlled by MPPT control. The output of PV module relies on the temperature, irradiation and output voltage. The $\left(\mathrm{V}_{\mathrm{oc}}\right)$ and $\left(\mathrm{I}_{\mathrm{sh}}\right)$ are the two main parameters applied which depicts the electrical performance of the cell.

\subsection{Analysis of solar PV cell performance with changing irradiance and temperature}

The expression irradiance is known as the measure of power density of sunlight given at a site on the earth in $\left(\mathrm{w} / \mathrm{m}^{2}\right)$, while the measure of energy density of sunlight known as irradiation. The two terms are associated to solar elements. With the increasing solar irradiance both $\left(\mathrm{V}_{\mathrm{oc}}\right)$ and $\left(I_{\text {sh }}\right)$ rises and therefore, the MPP changes.

Temperature plays other main factor in determine solar cell efficiency. As the temperature rises the average of photon generation rises therefore, the reverse saturation current rises fastly and this decreases the band gap.

Figures 4 and 5 display the impact of changes in parameters on the characteristic of PV module. Figure $4 a, b$ depict the simulation results of PV array (Array type: $C A$ Solar MS-150 M) by using MATLAB software for two curves $\mathrm{I}-\mathrm{V}$ and $\mathrm{P}-\mathrm{V}$ under four different irradiation from 0.25 to $1 \mathrm{~kW} / \mathrm{m}^{2}$ with constant temperature at $25^{\circ} \mathrm{C}$. We can observe that, the module current is proportionate to the radiation, whereas the $\mathrm{V}_{\mathrm{oc}}$ changes a bit with irradiation. Table 1 shows the values of various MPP through changing of irradiation, the MPP increases from 42.85 at 250 to 150 at $1000 \mathrm{~W} / \mathrm{m}^{2}$. Therefore, the rise of irradiation permits the increase of maximum power point.

Also, temperature is an important element in the behaviour of PV module. Figure $5 \mathrm{a}, \mathrm{b}$ depicts, the increase in temperature leads to a clear decrease in the $\mathrm{V}_{\mathrm{oc}}$.

Table 2 illustrates the values of various MPP through changing of temperature, the MPP decreases from 108 at $25^{\circ} \mathrm{C}$ to 150 at $75^{\circ} \mathrm{C}$. Therefore, the rises of temperature permits the reduce of the maximum power point.

\subsection{MPPT control techniques for PV system}

MPPT technique is applied to ameliorate the efficiency of solar panel, WT and they regulated to work at their point of maximum power. The MPPT algorithm relies on an initial reference of rotor speed for the WT and voltage for the PV array. The conformable power outputs for the two devices are measured. The delivered power by a PV device of one or more PV cells is depend on the three factors which are irradiance, temperature and current drawn from the cells. There are numerous techniques to maximizing the power from a PV device, several commonly traditional techniques for MPPT available in the literature [13-16], in general, the most widely-used are presented below:

\subsubsection{Constant voltage (CV) technique}

The CV method is the simplest control of MPPT algorithm and does not require any input. The working point of the PV array is recorded close to MPP by adjusting the array output voltage and convenient it to a constant reference voltage $V_{\text {ref }}$. The magnitude of $V_{\text {ref }}$ is regulating equal to the $V_{\text {MPP }}$ of the PV module or to other calculated better constant voltage. So, measurement of the $V_{P V}$ is needful to
Fig. 3 Modeling of photovoltaic system used in the Simulation

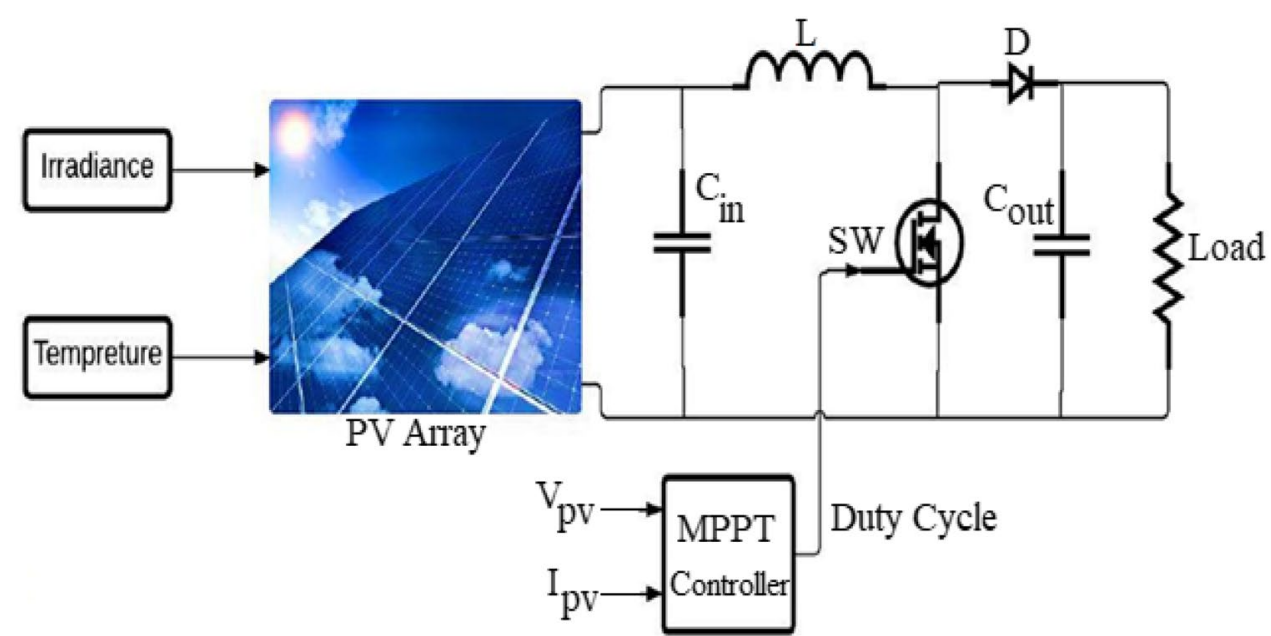

SN Applied Sciences A SPRINGER NATURE journal 
Fig. 4 Effect of various solar irradiations under constant temperature $\left(25^{\circ} \mathrm{C}\right)$
Fig. 5 Effect of various solar temperatures under constant irradiance $\left(1000 \mathrm{w} / \mathrm{m}^{2}\right)$

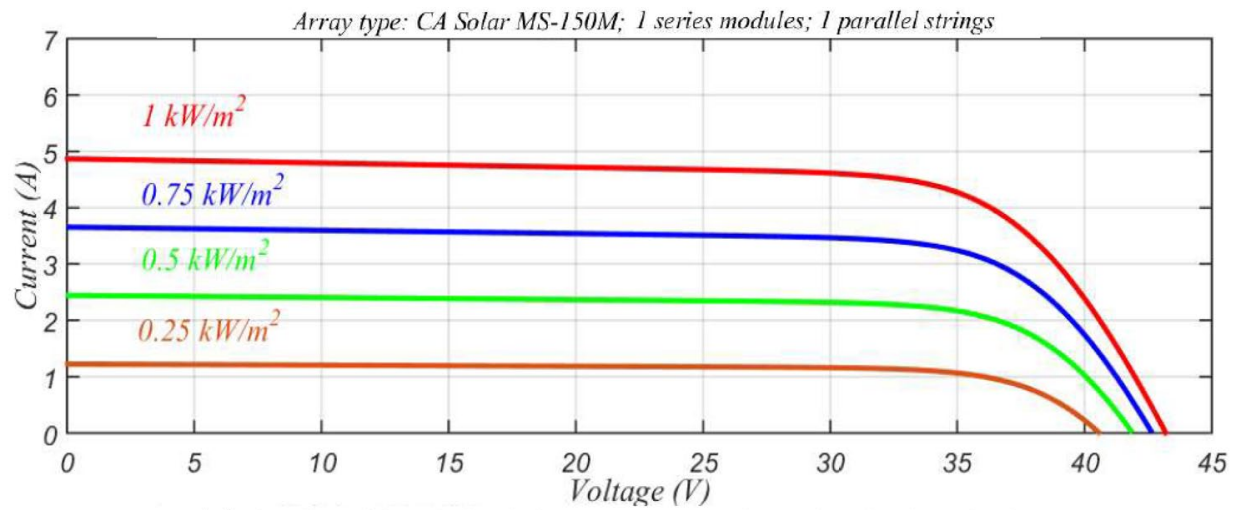

(a) The effect of the solar irradiation on I-V curve, at four various irradiance levels.

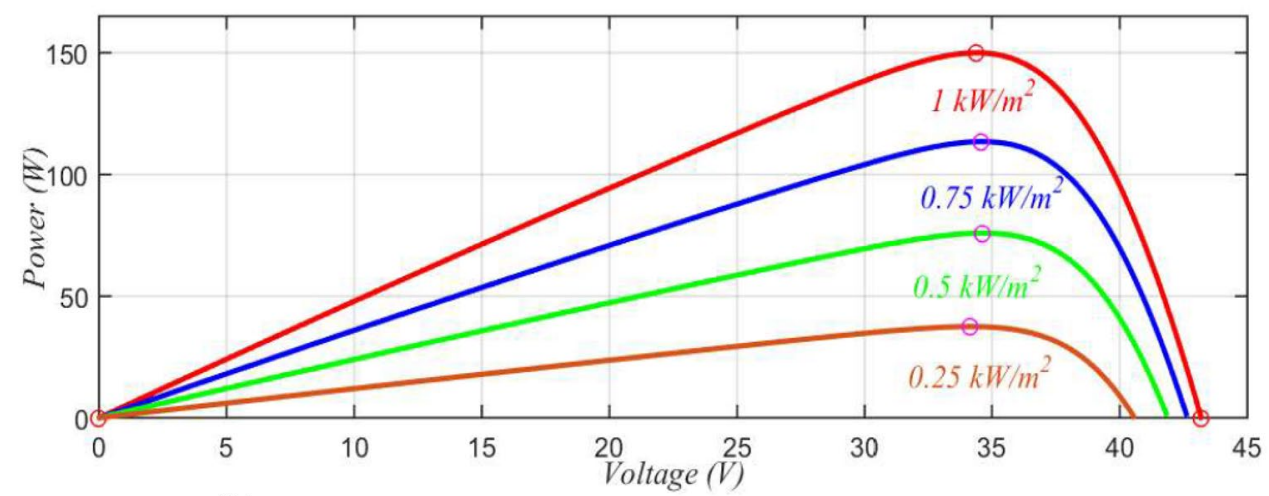

(b) The effect of the solar irradiation on $\mathrm{P}-\mathrm{V}$ curve, at four various irradiance levels.

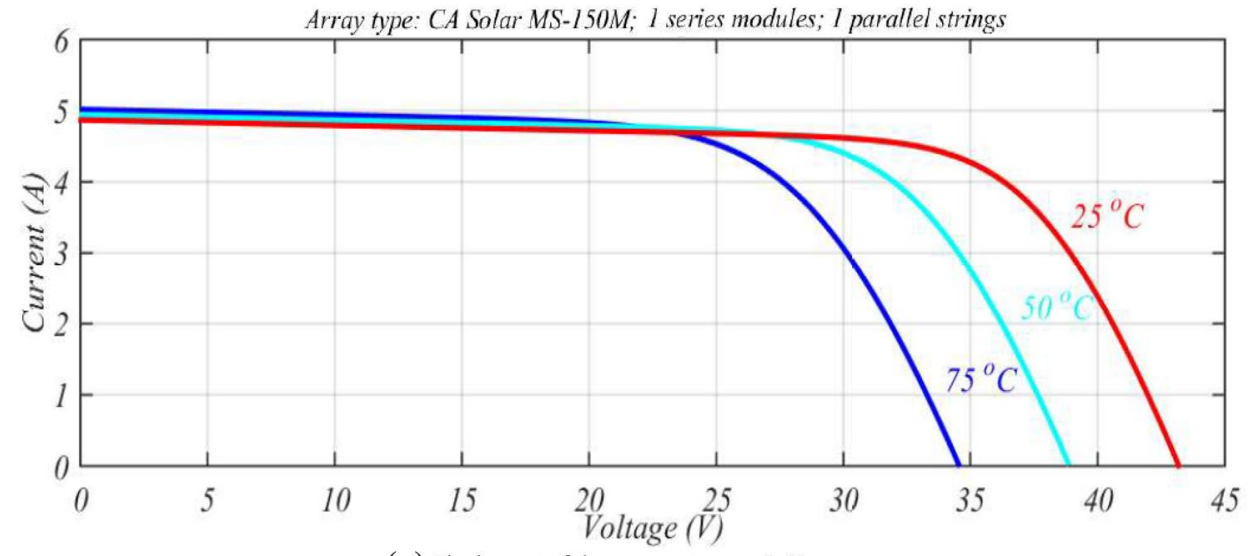

(a) The impact of the temperature on $\mathrm{I}-\mathrm{V}$ curve

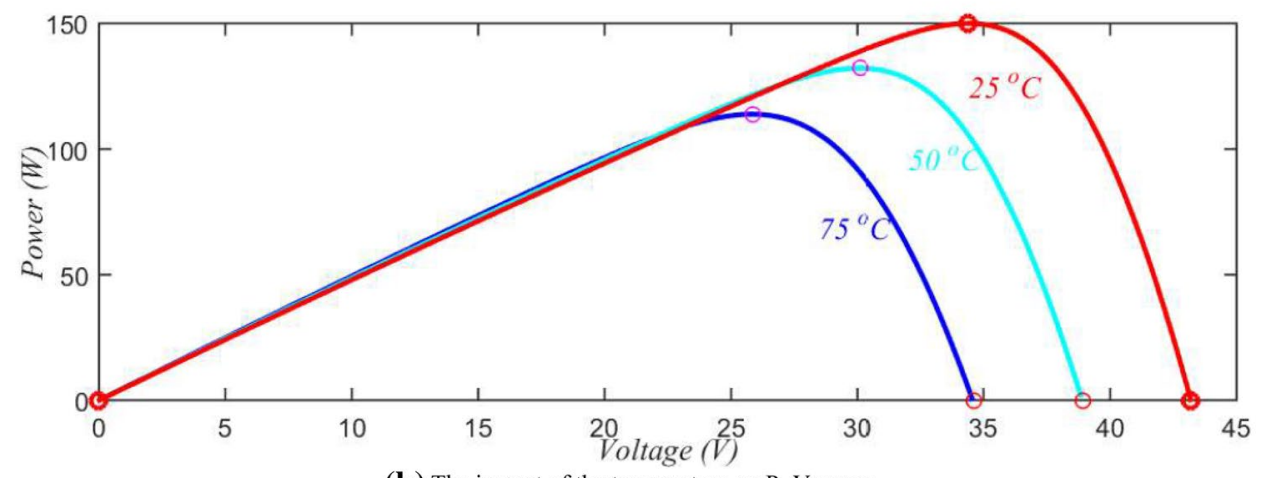

(b) The impact of the temperature on $\mathrm{P}-\mathrm{V}$ curve 
Table 1 Values of various MPP through changing of irradiation

\begin{tabular}{lllll}
\hline Irradiation in $\left(\mathrm{W} / \mathrm{m}^{2}\right)$ & 250 & 500 & 750 & 1000 \\
Power $(\mathrm{W})$ & 42.85 & 75 & 118.53 & 150 \\
\hline
\end{tabular}

Table 2 Values of various MPP through changing of temperature

\begin{tabular}{llll}
\hline Temperature in $\left({ }^{\circ} \mathrm{C}\right)$ & 25 & 50 & 75 \\
Power $(\mathrm{W})$ & 108 & 135.45 & 150 \\
\hline
\end{tabular}

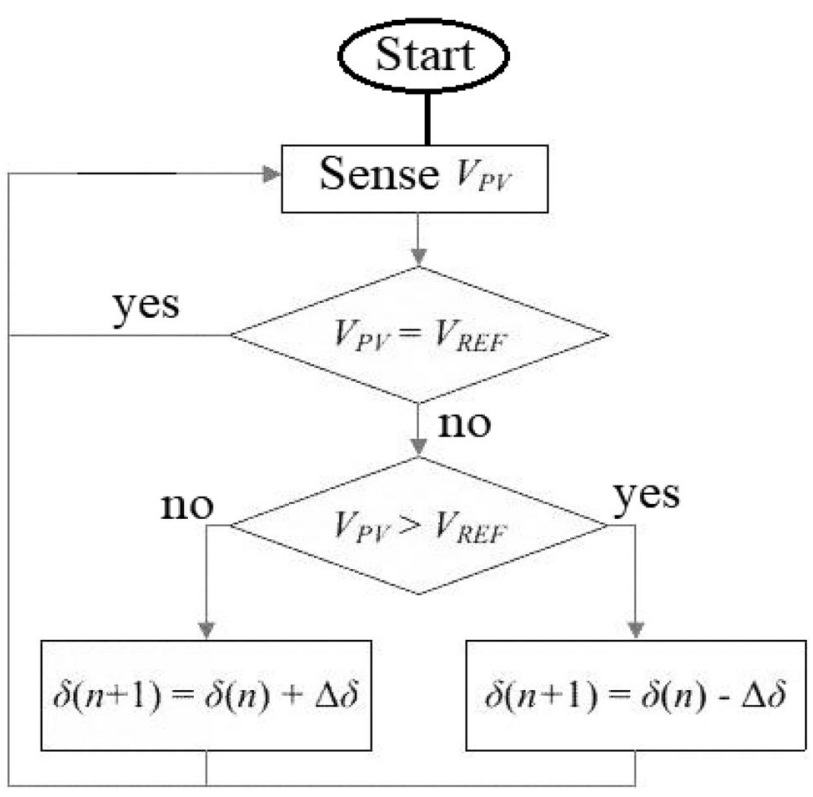

Fig. 6 Instruction flow chart for constant voltage technique

set up the duty-cycle of the dc/dc Sepic by PI organizer. It is important to notice that if the PV panel is in low insulation status, the CV algorithm is more effectual than the $\mathrm{P} \& \mathrm{O}$ or the INC methods. Constant voltage (CV) is sometime integrated jointly with other MPPT methods. The constant voltage (CV) is implemented using the instruction flowchart as indicated in Fig. 6.

\subsubsection{Short-current (SC) technique}

The SC technique realizes the MPP by awarding the optimal working current $\mathrm{I}_{\text {op }}$ to a current power converter controlled. Actually, the working current $\mathrm{I}_{\mathrm{op}}$ for maximum power output is commensurate to the short circuit current $\mathrm{I}_{\mathrm{SC}}$ at different status of irradiance level (S) as in Eq. (4):

$I_{o p}(s)=K \cdot I_{s c}(s)$

where $\mathrm{k}$ is a commensurate constant. Equation (4) depicts that $I_{o p}$ can be defined instantly by detecting $I_{S C}$. So, this

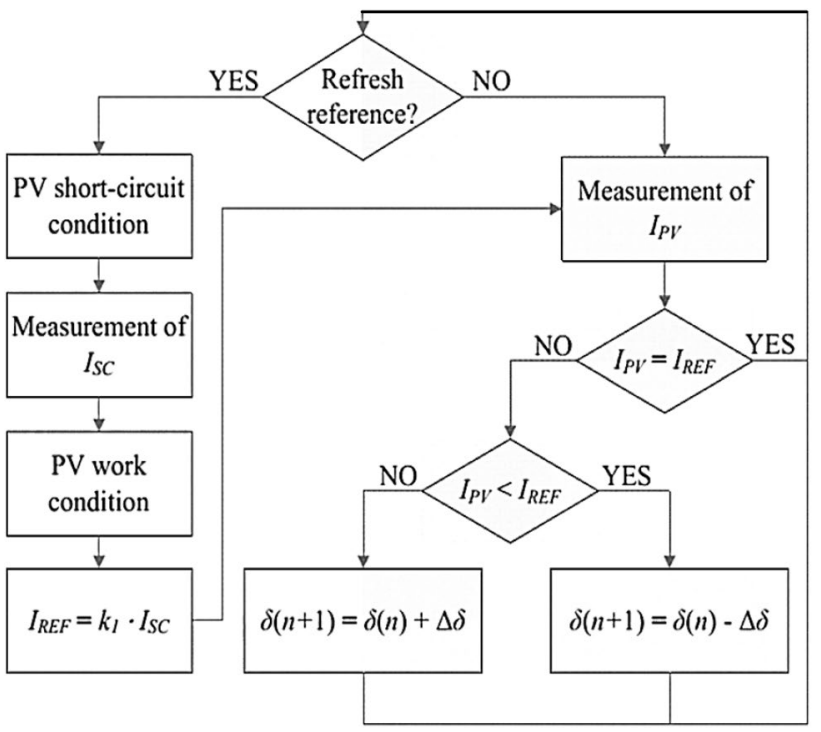

Fig. 7 Instruction flow chart for short-current technique

control technique needs measurements of $\mathrm{I}_{\mathrm{SC}}$. So, it is needful to insert a static switch in shunt with PV array, to make the short-circuit status. It is remarkable to reminder that, through the short-circuit $\mathrm{V}_{\mathrm{PV}}=0$ thus, no power is provided by the PV device and no energy is produced. As in the earlier method, mensuration of the PV array voltage is desired for the PI regulator to get the $V_{\text {ref }}$ magnitude able to produce the current $\mathrm{I}_{\mathrm{op}}$. The features of this technique it is simple, low cost to carry out and does not require an input. The demerits: irradiation is always properly at the MPP owing to differences on the array which are not appraised, data changes at different climate conditions and sites and also it has lower efficiency. The instruction flowchart of the SC method is illustrated in Fig. 7.

\subsubsection{Open voltage (OV) technique}

The OV algorithm is depend on the monitoring that the $V_{\text {MPP }}$ is constantly near a constant percentage of the $V_{O V}$. The $\mathrm{k}$ value is generally among $0.7-0.8$. It is needful to upgrade $\mathrm{V}_{\mathrm{OC}}$ sometimes to compensate any temperature change. This technique necessitates measurements of the $V_{\text {OV }}$ if the circuit is opened. Once more it is needful to insert a static switch to the PV device; for this method the switch should be inserted in series to open the circuit. If $\mathrm{I}_{\mathrm{PV}}=0$ no power is provided by the PV device and therefore no energy is produced. In this algorithm also measurement of the $V_{P V}$ is desired by the regulator. Figure 8 shows the instruction flowchart for this method. The merits of this technique are comparatively low cost, very simple to perform. The demerits are slower response, not precise and may not work punctually at maximum power point. 


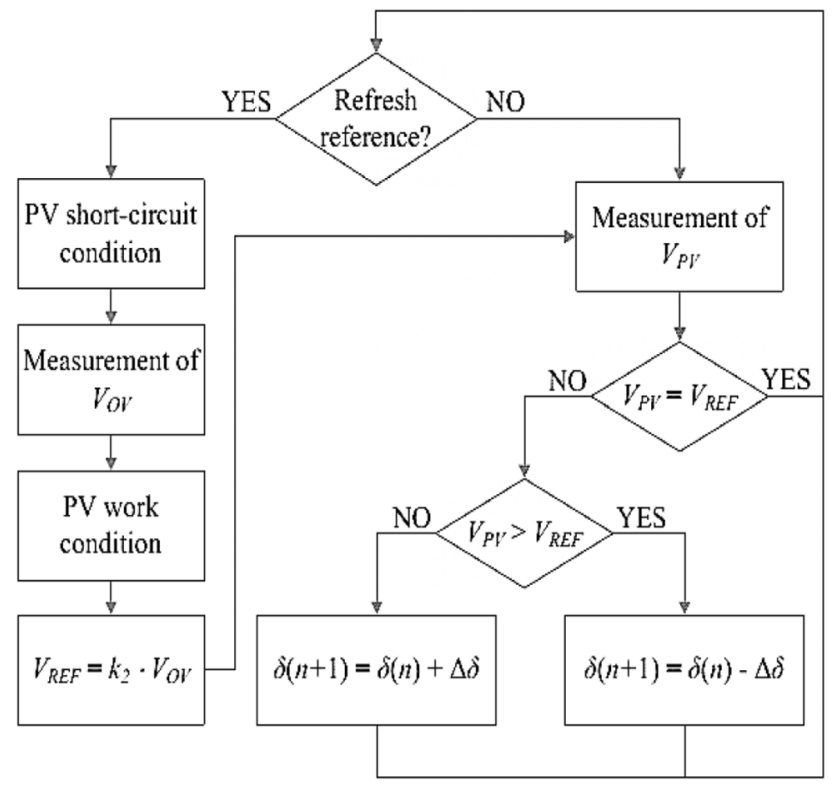

Fig. 8 Instruction flow chart for open voltage method

\subsubsection{Incremental conductance (INC) technique}

The INC is obtained by differentiation the power equation of $\mathrm{PV}$ module with regard to $(\mathrm{dP} / \mathrm{dV})$ and regulates the result equal to (0). The INC technique was formed to provide a best alternative to the $\mathrm{P} \& \mathrm{O}$ technique, the basic connotation of how the INC gets the MPP is depend on the slope of the power curve. At MPP the slope is zero, if the operating point in the $\mathrm{P}-\mathrm{V}$ plane is to the right of the maximum power point it is verified, whereas, if the working point is to the left of the maximum power point, we obtain:

$$
\begin{aligned}
& \left(d I_{p v} / d V_{p v}\right)+\left(I_{p v} / V_{p v}\right)=0 \\
& \left(d I_{p v} / d V_{p v}\right)+\left(I_{p v} / V_{p v}\right)<0 \\
& \left(d I_{p v} / d V_{p v}\right)+\left(I_{p v} / V_{p v}\right)>0
\end{aligned}
$$

The current, voltage of the solar cell and calculating the incremental conductance, the maximum power point voltage can be known as depicted in Fig. 9.

The maximum power point can be tracked down by compare $\mathrm{I}_{\mathrm{pv}} / \mathrm{V}_{\mathrm{pv}}$ to the incremental conductance $\mathrm{dl}_{\mathrm{pv}} / \mathrm{dV}_{\mathrm{pv}}$. The INC offers perfect performance at quickly changing atmospheric status where $I_{p v}$ and $V_{p v}$ are the PV array current and voltage, respectively. The instruction flowchart depicted in Fig. 10 illustrates the working of this technique. It begins with sensing the values of voltage and current PV module. Then, it computes the changes, $\Delta \mathrm{I}$ and $\Delta \mathrm{V}$ using the current and previous values. The merits of this method it can define the MPP without oscillating about this value.

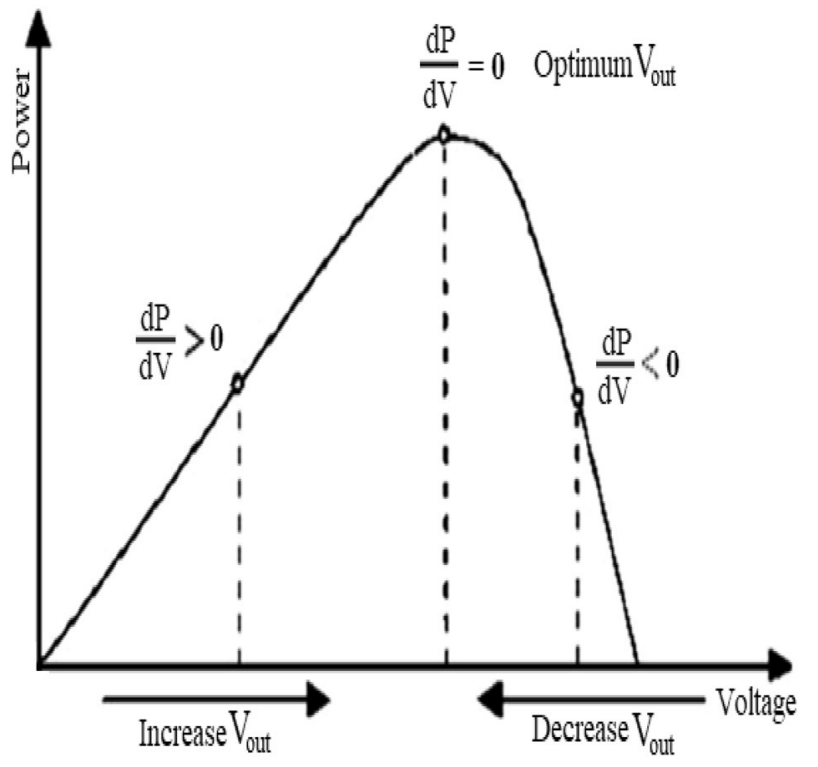

Fig. 9 Graph P-V curve for INC algorithm

The demerits are: increase the computational time owing to slow of the sampling frequency follow from the high complexity of the technique compared to the P\&O. Also the INC can perform unpredictably at rapidly changing atmospheric status.

\subsubsection{Perturb and observe (P\&O) technique}

This method has been chosen to carry out a MPPT technique owing to its clarity and the chance to introduce

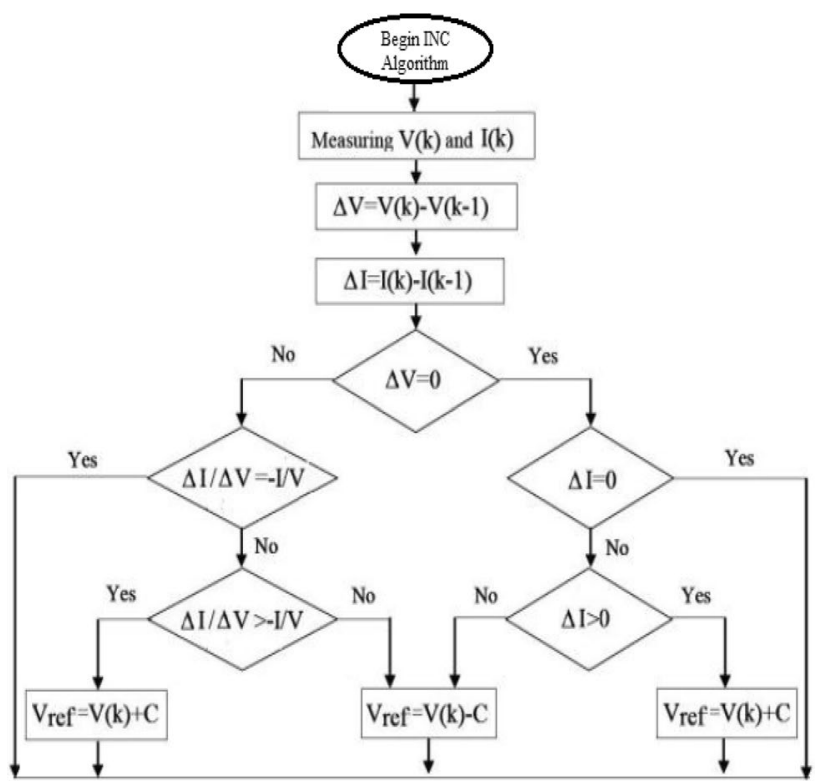

Fig. 10 Instruction flowchart for the INC technique 
improvements. In this technique, $\mathrm{PV}$ voltage and current $\mathrm{V}(\mathrm{k}), \mathrm{I}(\mathrm{k})$ are measured. Then power is studied $\mathrm{P}(\mathrm{k})$ and compared with the power studied in the former sample $P(k-1)$ to obtain on $\Delta P$. When the outcome of $\Delta P$ is $(0)$, the system is operating in MPP. On the other hand and according to the signs of $\Delta \mathrm{P}$ and $\Delta \mathrm{V}$ to control the duty cycle (a) will be reduce or increase to force the operating point of the PV module across the maximum power point. The instruction flowchart depicted in Fig. 11 illustrates the operation of this technique.

The cell voltage is increased at first when the output power increased, the voltage is regularly increased till the power output begins reducing and then the voltage to the cell reduced till maximum power is reached. This outcome is a vibration of the output power about the MPP. Figure 12 depicts the PV module's output power versus voltage using $\mathrm{P} \& O$ algorithm. Assume that, PV module is working at a point that is far from the MPP. The voltage of PV module in this technique is perturbed by a little increment and the change in power, $\mathrm{P}$ is noticed. So, the operating point can be on the left hand side "+ve slope", middle point "MPP" or right hand side"-ve slope". For this research we choose the $\mathrm{P} \& \mathrm{O}$ method as it has more advantages over demerits such as, ease of application, low cost and it's usually applied technique in PV and wind turbines applications.

\subsection{Boost converter topologies}

Consider a boost converter circuit diagram attached to a PV system with a resistive load as illustrated in Fig. 13, the main components used to carry-out are an inductor, diode,

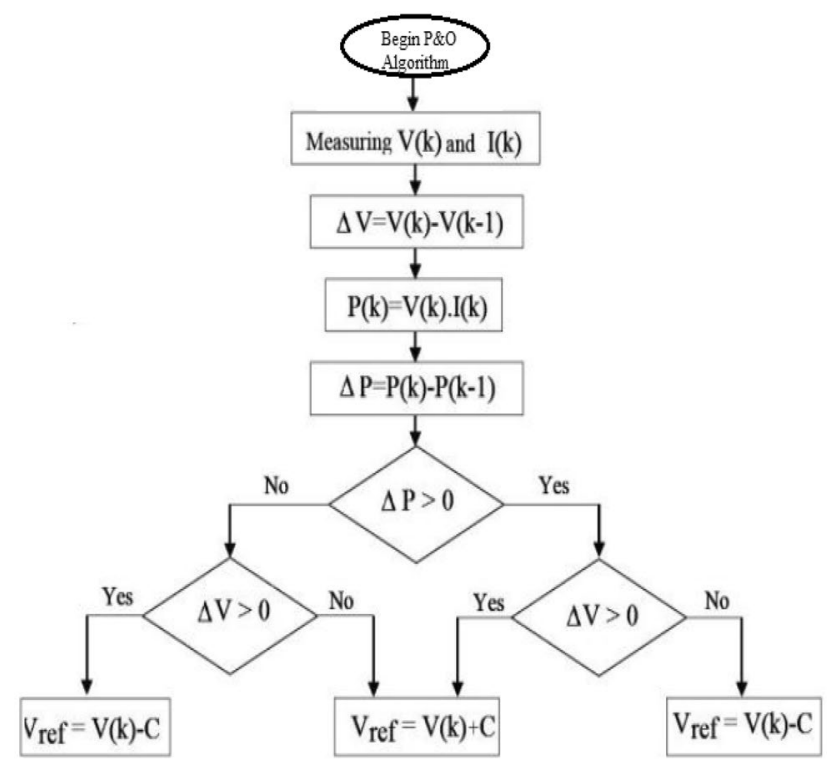

Fig. 11 Instruction flowchart for the (P\&O) algorithm

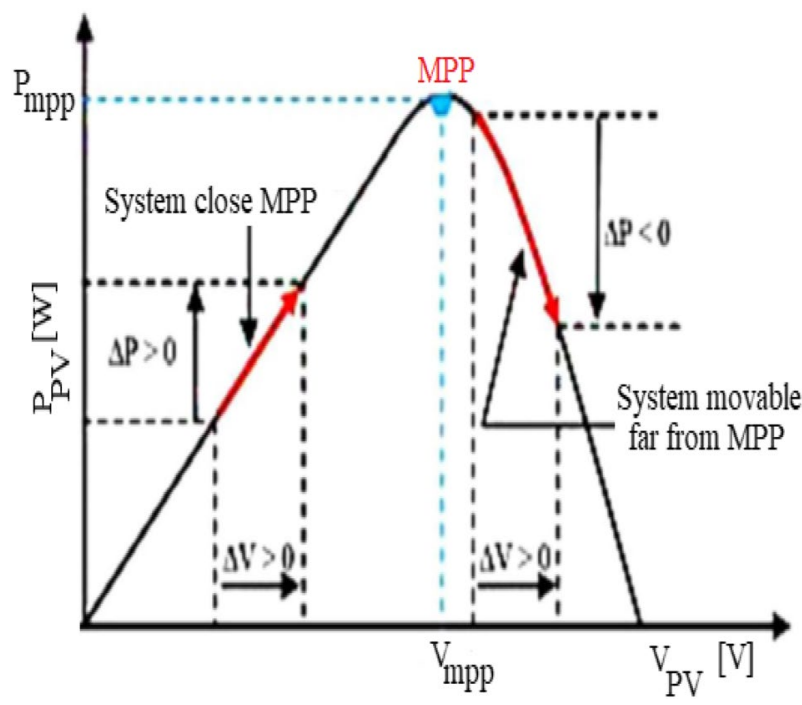

Fig. 12 Graph output power versus voltage using P\&O algorithm

capacitor and a high frequency switch. Converter unit steps up the input voltage value to the desired voltage output without using of a transformer.

These coordination methods provide power to the load at a voltage greater than the input voltage to the boost converter. The charging current increases exponentially, but assumes linear increases for simplicity. The first step to compute the switch current is to define the duty cycle for the input voltage which used because this produce the maximum switch current.

$D=1-\frac{V_{\text {in }} \times \eta}{V_{\text {out }}}$

where $D=$ duty cycle, $V_{\text {in }}=$ typical input voltage, $V_{\text {out }}=$ desired output voltage, $\eta=$ converter efficiency. The $(\eta)$ is added to the equation, because the converter has to transfer the energy dissipated. This computation gives a more factual duty cycle than quite the equation without (n). The following step to calculate the switch current in order to determine the inductor ripple current.

$\Delta L=\frac{V_{\text {in }} \times D}{L \times f_{s}}$

where $f_{s}=$ converter switching frequency, $L=$ chosen inductor value. This equation is a good assessment for the suitable inductor:

$L=\left(\frac{V_{\text {in }} \times\left(V_{\text {out }}-V_{\text {in }}\right)}{\Delta L \times f_{s} \times V_{\text {out }}}\right)$. 
Fig. 13 Circuit topology for boost converter

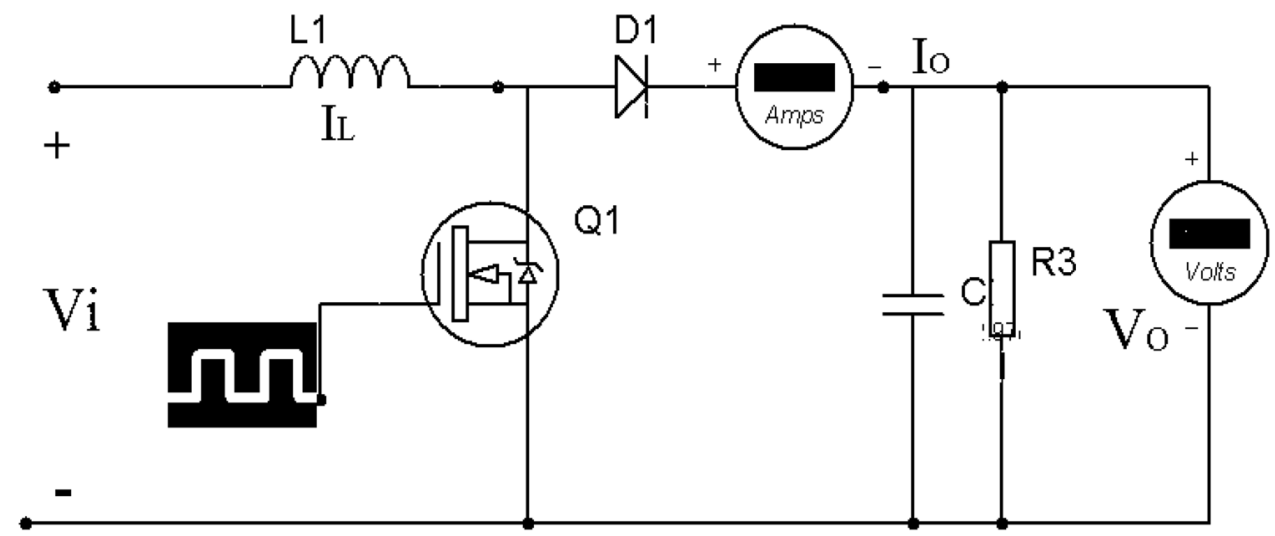

\section{Modeling analysis of (WECS) configuration}

The modeling of WECS under study composed of a gearless WT directly coupled to PMSG with uncontrolled 3-phase rectifier and converter unit as depicted in Fig. 14. The PMSG has the merit of being directly inserted to a WT with no necessity for a gear box, there is no requirement for excitation current as in the double fed induction generator (DFIG) case and there is no direct linkage among the generator and the utility grid for network tie applications. The PMSG composed of 3-phase stator winding like squirrel cage induction generator $(\mathrm{SCIG})$, whereas the rotor winding is changed by the permanent magnet (PMs). the merit of eradicate the rotor field winding are copper losses decrease, power density is higher and low rotor inertia, the disadvantages are high costs and loss of flexibility in flux control and change parameter with traffic of time $[17,18]$.

In this scenario, a resistor is applied as the load and the MPP will be indicated into maximum voltage through it. The diode bridge rectifier is utilized instead of a 3-phase controlled PWM in order to its low cost and high reliability. This section presents the WT converts the wind power into mechanical power in the rotor shaft.
Thereafter, converted into electricity by using a PMSG. The voltage created by the PM machine is rectified by using a 3-phase passive rectifier that converts the $A C$ voltage produced by the PMSG to a DC voltage.

To explain WTs power characteristic, Eq. (11) presents the mechanical power output which is created by the wind turbine:

$P_{T}=0.5 \times A \times \rho \times C_{P}(\lambda, \beta) \times v_{w}^{3}$

In this article, owing to the hypothesis of a constant pitch rotor, the pitch angle $\beta$ is set $(0)$, the relation of $C_{p}$ depend mainly on $\lambda$ when $\beta$ equal zero degree. Figure 15 depicts the power coefficient $\left(C_{p}\right)$ of the wind turbine versus tip speed ratio $(\lambda)$. Observed that, the $C_{p}$ optimum value is approximately 0.48 for $\lambda$ equal to 8.1 , the performance coefficient of a WT is affected by the ratio of tipspeed to wind-speed, as follows:

$\lambda=\frac{\omega_{m} \times R}{v_{w}}$

where $\rho$ : Air density, $\mathrm{kg} / \mathrm{m}^{3}, A$ : Area of the circle swept by the rotor $\left(\mathrm{m}^{2}\right) . z$, $\lambda$ :Tip speed ratio of the wind system, $\lambda_{\mathrm{opt}}$ : optimal tip speed ratio, $\beta$ : Pitch angle (degree), J: Moment of inertia, $\mathrm{kg} \mathrm{m}^{2}, \mathrm{~W}$ : Turbine rotor speed in ( $\left.\mathrm{rad} / \mathrm{s}\right)$.
Fig. 14 Modeling of wind turbine system used in the Simulation

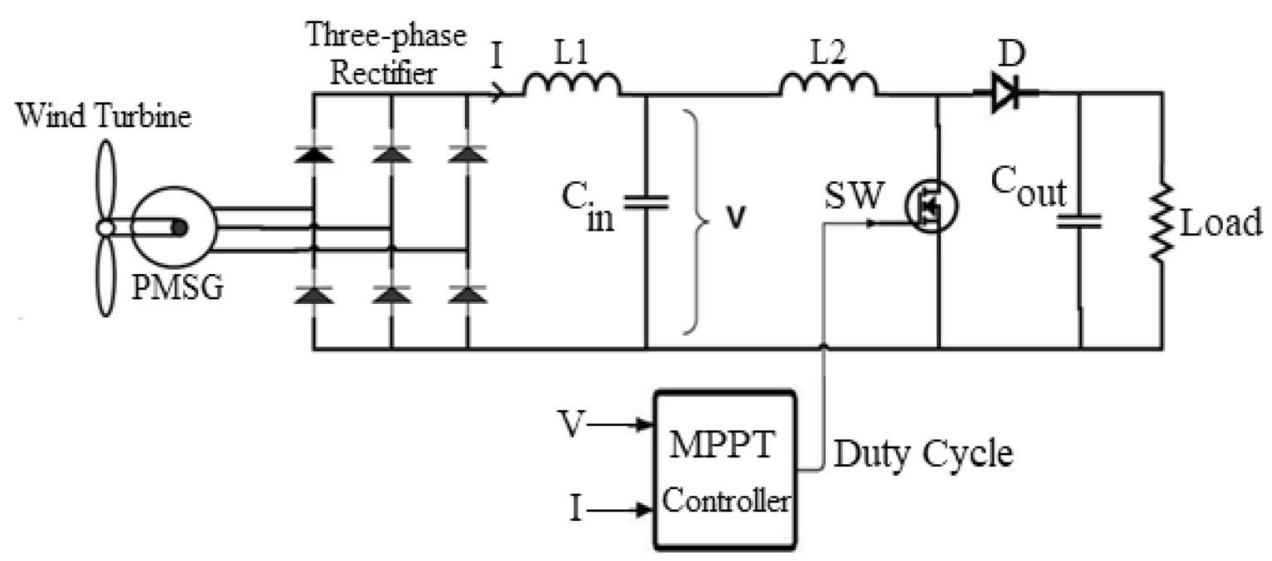




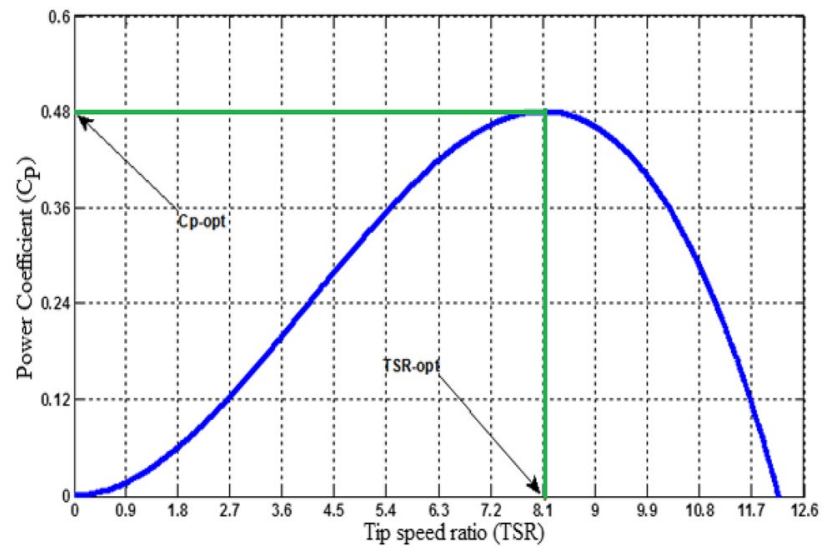

Fig. 15 Power coefficient $(C p)$ versus tip speed ratio $(\lambda)$

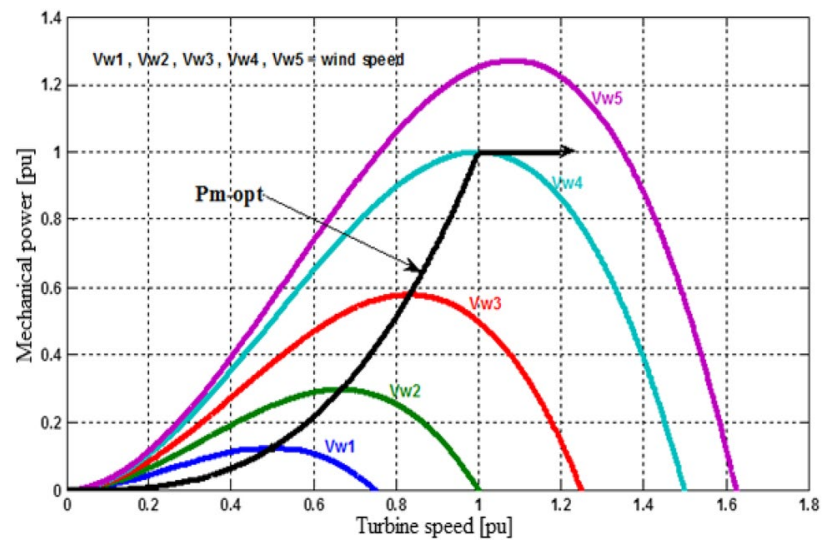

Fig. 16 Power curves for a typical WT with different wind speeds

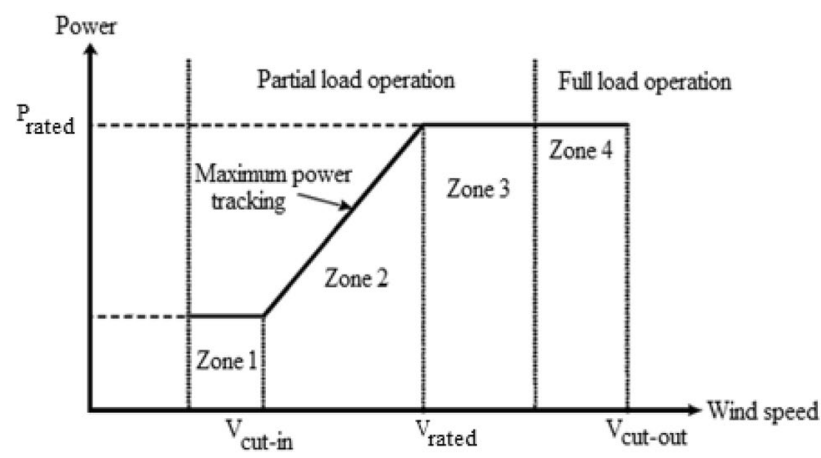

Fig. 17 Power curve of turbine speed control zones

Figure 16 illustrates the relationship among mechanical powers created by the turbine and wind rotor speed at various speeds of the wind. It is noticed that, the MPP varies with the variation of wind speed. The WT can generate maximum power if the turbine works at $C_{p}$ optimum value $\left(C_{p-o p t}\right)$. Therefore, it is requisite to set the rotor speed at optimum rate of the tip speed ratio $\left(\lambda_{\text {opt }}\right)$.
The wind turbine control zones most generally used is shown in Fig. 17 and consists of four operation zones. Zones $(1,3)$ represent the minimum and maximum speed operation of control. In this operation zone, the main function is to keep a constant speed of rotation of the turbine at its minimum value in zone 1 and zone 3 . Zone (2) describes the maximum power tracking. In this operation zone, the purpose of the speed control is to follow the track of maximum power extraction from variable speed operation with partial load. Zone (4) represents the power control. The main objective of this zone, limit the maximum operating speed at rated output power and the electromagnetic torque is held constant at its nominal value [19].

\subsection{Control of MPPT techniques for WECS}

There are numerous techniques for tracking MPP such as tip speed ratio (TSR), power signal feedback (PSF), hillclimb search (HCS) and optimal torque control as illustrated in Fig. 18 [20-22].

\subsubsection{Tip speed ratio (TSR)}

In this type, it is desired to retain up the tip speed ratio (TSR) to an optimum value that extracted power is maximized by adjusting the rotational speed of the generator. In this case, optimal point can be known theoretically or experimentally and save as a reference. Although however, this type is fast response. However, the requisite of an accurate anemometer for measuring the speed of the wind causes the system more costly, especially for small scale of a WECS. Figure 18a depicts block diagram of a WECS with TSR algorithm.

\subsubsection{Power signal feedback (PSF)}

The PSF requires the familiarity of WT maximum power curve that is tracked by its control mechanisms. The maximum power curves can be given through simulation or experimental tests on individual WTs. Figure 18b illustrates block diagram of a WECS with PSF algorithm. In this case, $P_{m \text {-opt }}$ is created by using a pre get power-speed curve. Wherever wind speed or the turbine speed is applied as the input. The controller decreases the error among optimum power and actual power.

\subsubsection{Hill-climb search (HCS)}

The HCS is a mathematical optimization strategy applied to search for the local optimum point of a specific function. It is broadly applied in WECS by searching the optimal working point to extract maximum power. This control 


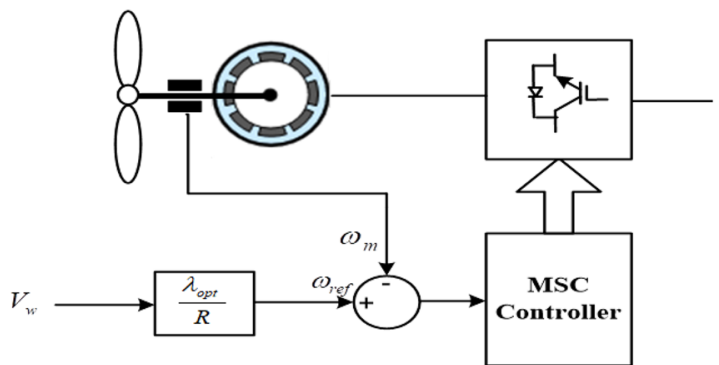

(a) WECS with TSR control algorithm

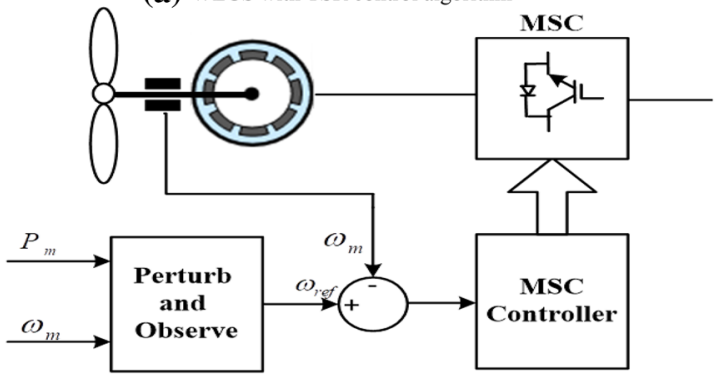

(c) WECS with HCS control algorithm

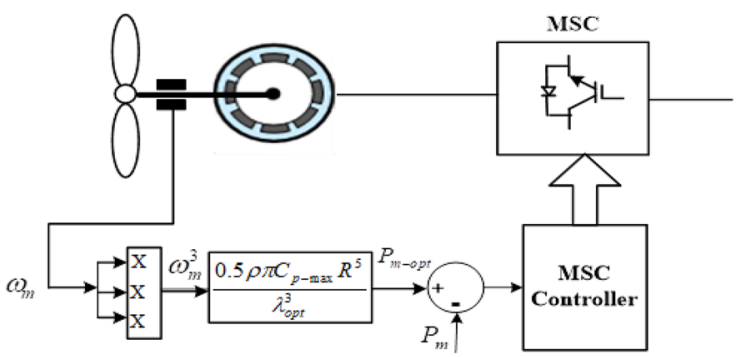

(b) WECS with PSF control algorithm

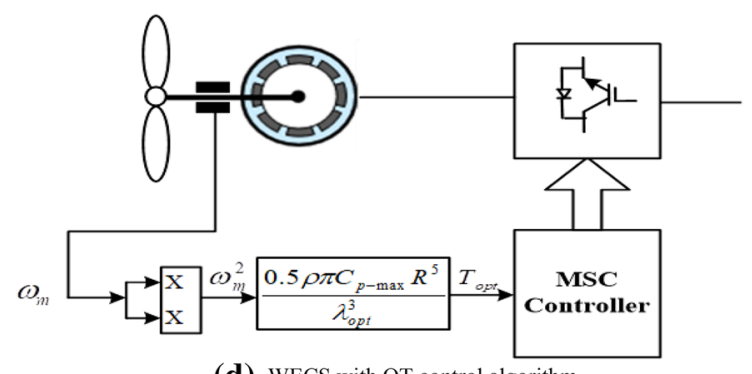

(d) WECS with OT control algorithm

Fig. 18 MPPT control algorithms for WECS

depends on perturbing a control variable in small stepsize as depicted in Fig. 18c. The HCS control does not need prior knowledge of the WTs characteristic curve; it is simple and flexible. So, it fails to reach the points of maximum power at fast wind variations when applied for medium and large inertia WTs.

\subsubsection{Optimal torque (OT)}

In OT the generator torque is controlled to get optimum reference torque curve according to $P_{\max }$ of the WT at a specific wind speed. Figure 18d depicts block diagram of a WECS with OT algorithm. Therewith, this control is widely applied in WECS. Furthermore, the OT curve that obtained mainly via experimental tests will change if the system ages and affect the efficiency of MPPT.

The optimal rotational speed of the WT can be formulated as follows:

$\omega_{m-o p t}=\frac{\lambda_{o p t}-V_{W}}{R}$

$P_{m-o p t}=0.5 \rho A C_{p-o p t}\left(\frac{\lambda_{o p t}-V_{w}}{R}\right)^{3}$

$P_{m-o p t}=K_{p-o p t}\left(\omega_{m-o p t}\right)^{3}$
So, the term for optimum torque of the turbine can be expressed as:

$T_{m-o p t}=0.5 \rho \pi R^{5} \frac{W_{o p t}^{2}}{\lambda_{o p t}^{3}}=K_{p-o p t} \omega_{o p t}^{2}$

where $\mathrm{K}_{\mathrm{opt}}$ : Constant determined by the WT and $\mathrm{P}_{\mathrm{m} \text {-opt }}$ : Optimal power curve, $C_{p}$ : Non-dimensional power coefficient of the WT.

The enforcement of MPPT methods mainly requires mechanical sensors in order to measure wind and rotor speeds. Unluckily, the utilize of mechanical sensors requires much more maintenance in addition to their high costs. Thus, a new technique has appeared to ameliorate the efficiency of wind turbine like sensor-less control. The relationship between generator speed, parameters of PMSG, $V_{d}$ and $I_{d}$ is given by:

$\omega_{g}=\frac{2 \pi\left(V_{d}+2 R_{s} I_{d}\right)}{60\left(\frac{3 \sqrt{ } 3}{\pi} K_{m}-\frac{p}{2} L_{s} I_{d}\right)}$.

\section{Maximum power control of hybrid generation system}

Integrating both solar energy and wind gives a more suitable and dependable system and also can provide power sharing between them at any climate conditions. Wind system is supplying large amounts of energy but, its existence is highly uncertain. Also solar panel is present during the 
day but, the solar irradiation varies owing to shadow and sun intensity. Figure 19 depicts the hybrid system used in the simulation study.

\subsection{Multi-input rectifier topology}

In this part a new idea for a modular inverter design is depicted for power system that inputs power from ac and dc renewable sources. This topology is the collection of Cuk-Sepic converters, where the input can be buck, boosted, stabilized at the specific value, the inductor is used in order to reducing harmonics. The features of the suggested design are: MPPT can be realized for every source, it can backup wide ranges of solar and wind input and simultaneous running is supported. The proposed circuit diagram of multi-input rectifier for a hybrid (sola and wind) is depicted in Fig. 20, one of the inputs is inserted to the output of PV array and another input
Fig. 19 Schematic diagram of hybrid system used in the simulation study
Fig. 20 Proposed circuit diagram of multi-input rectifier topology for a hybrid system (solar and wind)
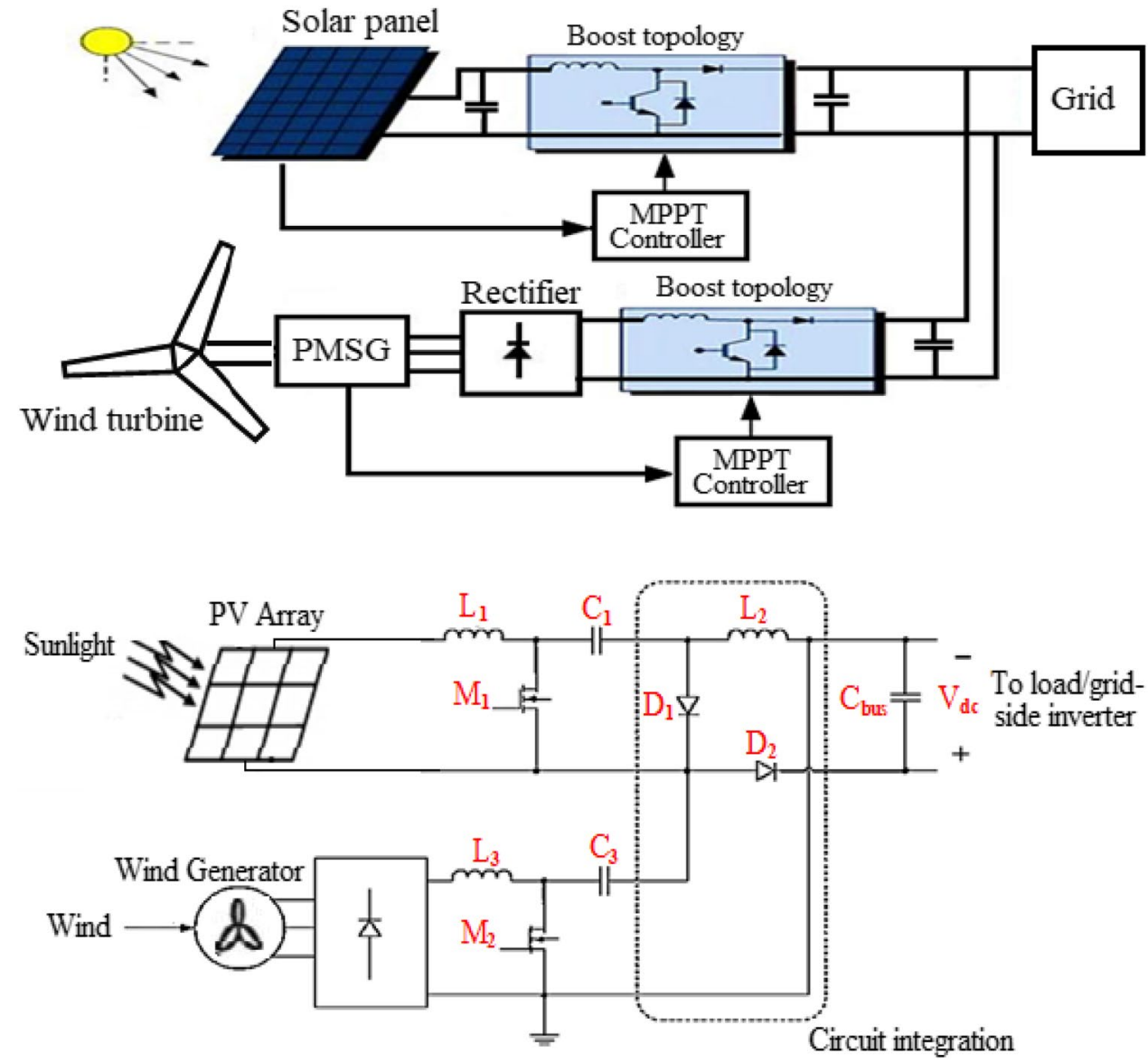

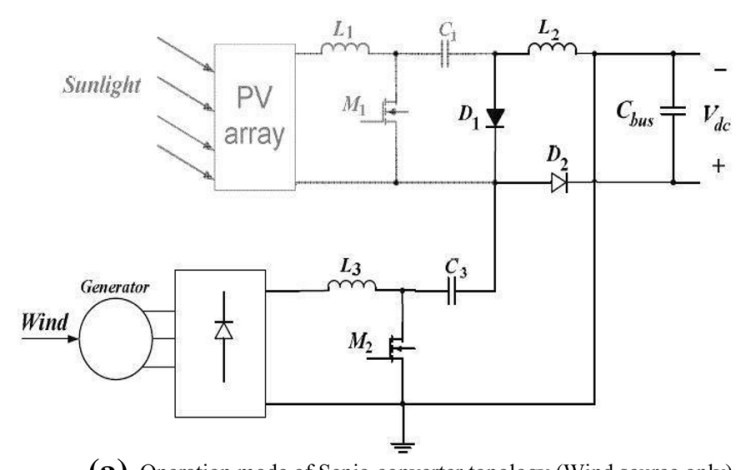

(a) Operation mode of Sepic-converter topology (Wind source only)

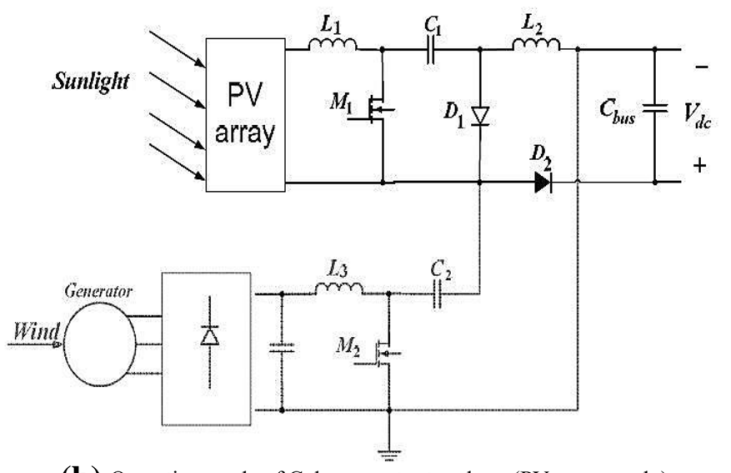

(b) Operation mode of Cuk-converter topology (PV source only)

Fig. 21 a Operation mode of Sepic-converter topology (wind source only). b Operation mode of Cuk-converter topology (PV source only) 
is inserted to the output of a wind system. The fusion of these topologies is done by reconfiguring the two diodes $\left(D_{1}, D_{2}\right)$ from every converter topology. This configuration permits each topology to work normally singly within the case which one source is unavailable $[23,24]$.

Figure 21 a depicts if only the wind supply is available where $D_{1}$ turn-off and $D_{2}$ will always be on, the suggested circuit diagram be a Sepic-converter, the relation among the input to output voltage is expressed by Eq. (18).

$\frac{V_{d c}}{V_{w}}=\frac{d_{2}}{1-d_{2}}$

Furthermore, when only the PV supply is available, in this case $D_{2}$ turn-off and $D_{1}$ turns on and the suggested circuit diagram are a Cuk-converter as depicted in Fig. 21 b. The relation between input to output voltage is expressed by Eq. (19). In two cases, each converter has step-up or step-down which provides more design flexibility within the system when duty ratio control is employed to implement MPPT management.

$\frac{V_{d c}}{V_{P V}}=\frac{d_{1}}{1-d_{1}}$

\subsection{Modes of operation}

Figure 22 presents the several switching states of the suggested converter. When the turn on interval of $M_{1}$ is longer than $M_{2}$, the switching will be state I, II, IV. Likewise, the switching will be state I, III, IV when the switch conduction intervals are conversely. For best explanation, the inductor current waveforms of every switching state are set as follows supposing that $d_{2}>d_{1}$, therefore only states I, III, IV are illustrated in this example. In this case, $\mathrm{I}_{\mathrm{i}, \mathrm{PV}}$ is the average current from PV supply, $\mathrm{I}_{\mathrm{i}, \mathrm{W}}$ is the RMS current after the rectifier (wind state) and $I_{d c}$ is the average output current. The key waveforms which present the switching states are illustrated in Fig. 23.

The mathematical model which relates the output voltage and the input sources $\left(\mathrm{V}_{\mathrm{W}}\right.$ and $\left.\mathrm{V}_{\mathrm{PV}}\right)$ will be given as follows:

State I (M1 on, M2 on):

$i_{L 1}=I_{i, p v}+\frac{V_{p v}}{L_{1}} t \quad 0<t<d_{1} T_{s}$

$i_{L 2}=I_{d c}+\frac{v_{c 1}+v_{c 2}}{L_{2}} t \quad 0<t<d_{1} T_{s}$

$i_{L 3}=I_{i, w}+\frac{V_{w}}{L_{3}} t \quad 0<t<d_{1} T_{s}$
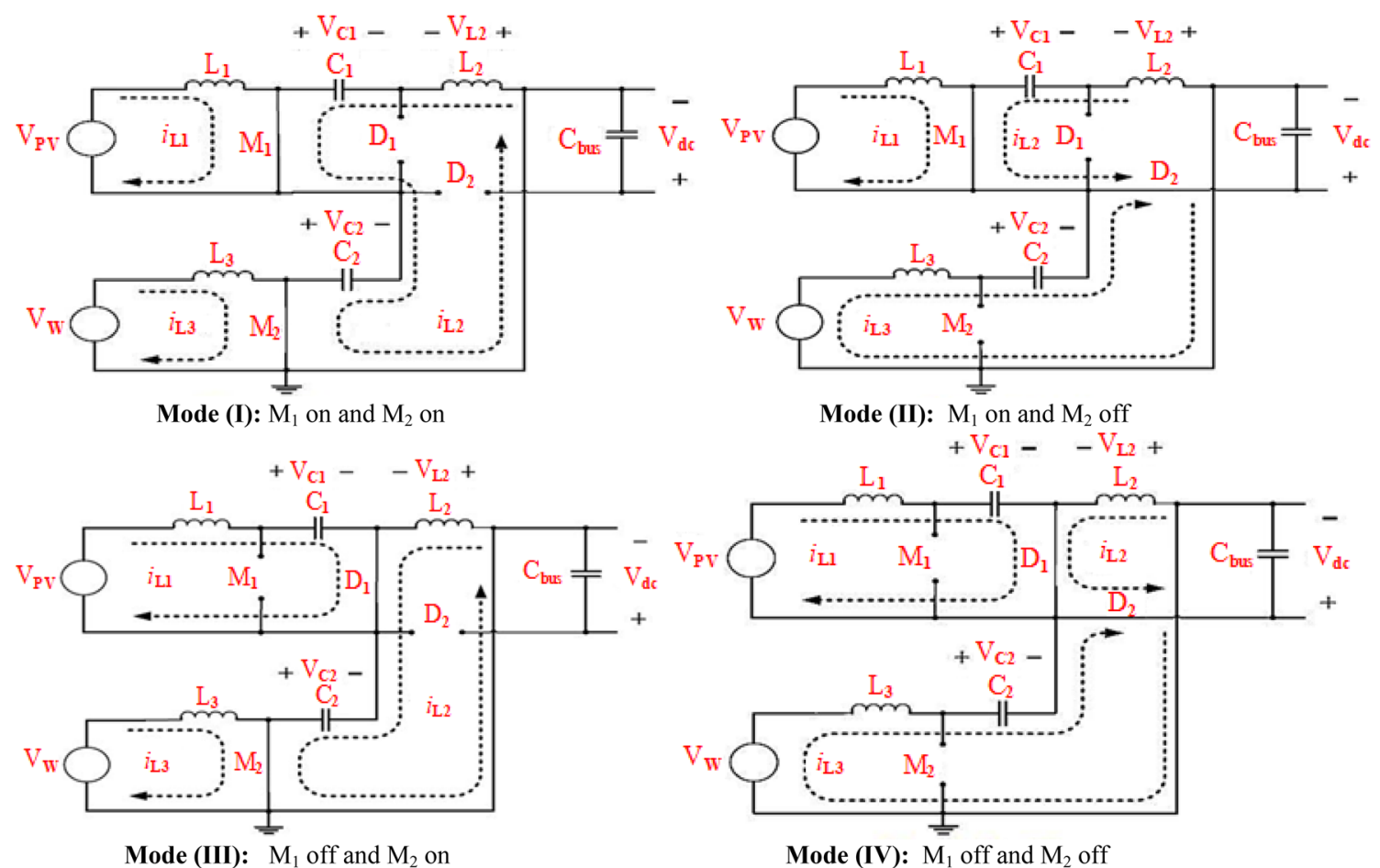

Mode (II): $\mathrm{M}_{1}$ on and $\mathrm{M}_{2}$ off

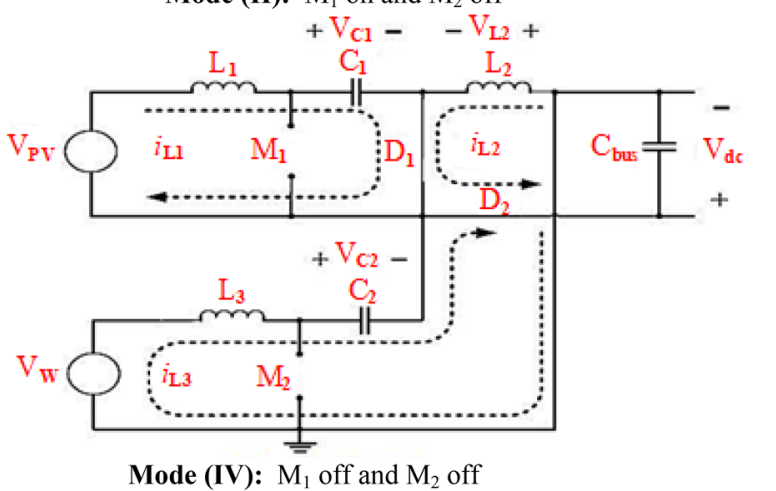

Fig. 22 Different switching states (I-IV) of the proposed multi-input rectifier topology 
Fig. 23 key waveforms switching states

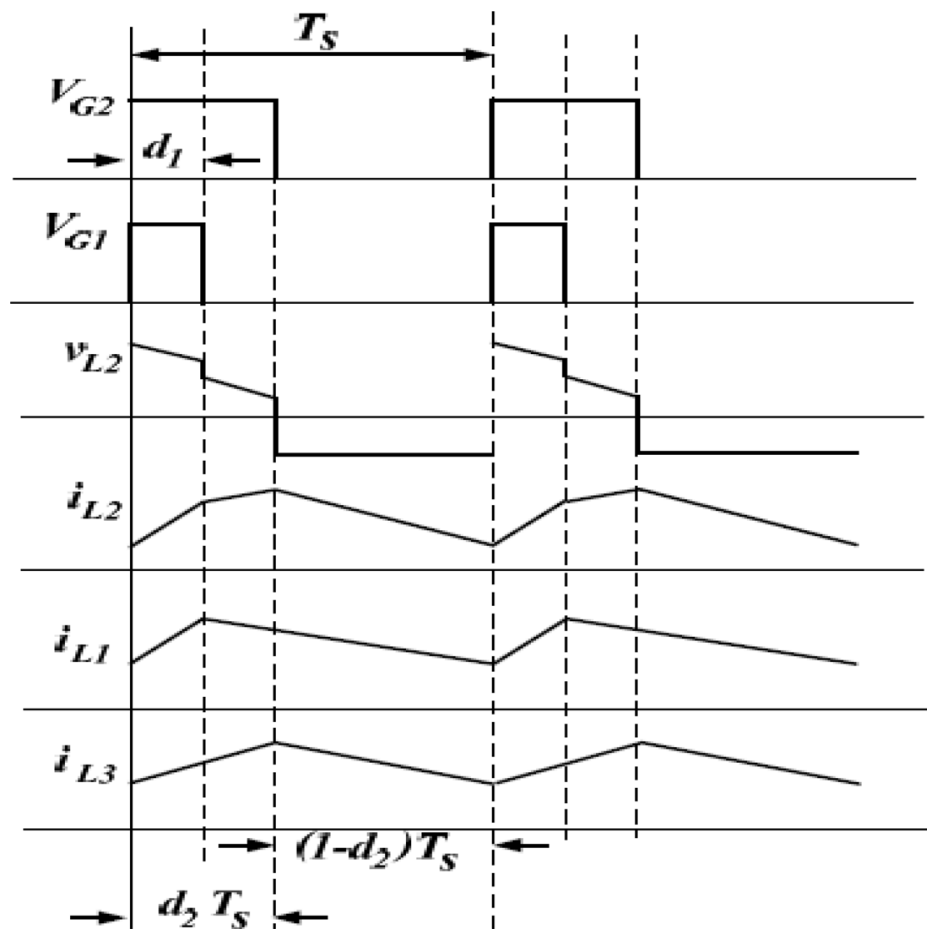

This system design is analysed under different environmental conditions like variation of solar radiation and wind speed. This section is divided into three case studies: performance of the PV system, performance of wind energy and performance of hybrid system (PV-wind). The simulation results illustrated which the suggested control strategies achieved the desired system performance. The parameters applied in the simulation study are:

1. Parameters of PV Array

State IV (M1 off, M2 off):

$i_{L 1}=I_{i, w}+\frac{v_{w}-v_{c 2}-v_{d c}}{L_{3}} t \quad d_{2} T_{s}<t<T_{s}$

$i_{L 2}=I_{d c}-\frac{v_{d c}}{L_{2}} t \quad d_{2} T_{s}<t<T_{s}$

$i_{L 1}=I_{i, p v}+\frac{v_{p v}-v_{c 1}}{L_{1}} t \quad d_{2} T_{s}<t<T_{s}$.

\section{Simulation analysis and results}

The complete system design of hybrid power system used here is inserted to the electrical grid that including PV and wind turbine system with multi-input rectifier topology. Simulation is done by using MATLAB Simulink software. The MPPT was modeled for the hybrid system (Wind-PV).
Module: CA Solar MS-150 M, Maximum Power $\left(P_{\max }\right): 150 \mathrm{~W}$

Open circuit voltage $\left(\mathrm{V}_{\text {oc }}\right): 43.2 \mathrm{~V}$, Short-circuit current $\left(I_{\mathrm{sc}}\right): 4.87 \mathrm{~A}$

Voltage at MPP $\left(\mathrm{V}_{\mathrm{mp}}\right): 34.4 \mathrm{~V}$, Current at MPP $\left(\mathrm{I}_{\mathrm{mp}}\right)$ : $4.36 \mathrm{~A}$

Cells per module $\left(\mathrm{N}_{\text {cell }}\right): 72$, Standard Operating Temperature: $25^{\circ} \mathrm{C}$

Maximum irradiance level: $1000 \mathrm{~W} / \mathrm{m}^{2}$

2. Parameters of Wind System

Type of generator: PMSG, Rated output power: $3000 \mathrm{~W}$

Stator winding: Star connection, Number of pole pairs: Four

Frequency: $50 \mathrm{~Hz}$, Stator resistance: $0.43 \Omega$ /phase and Armature inductance: $8.35 \mathrm{mH}$ 


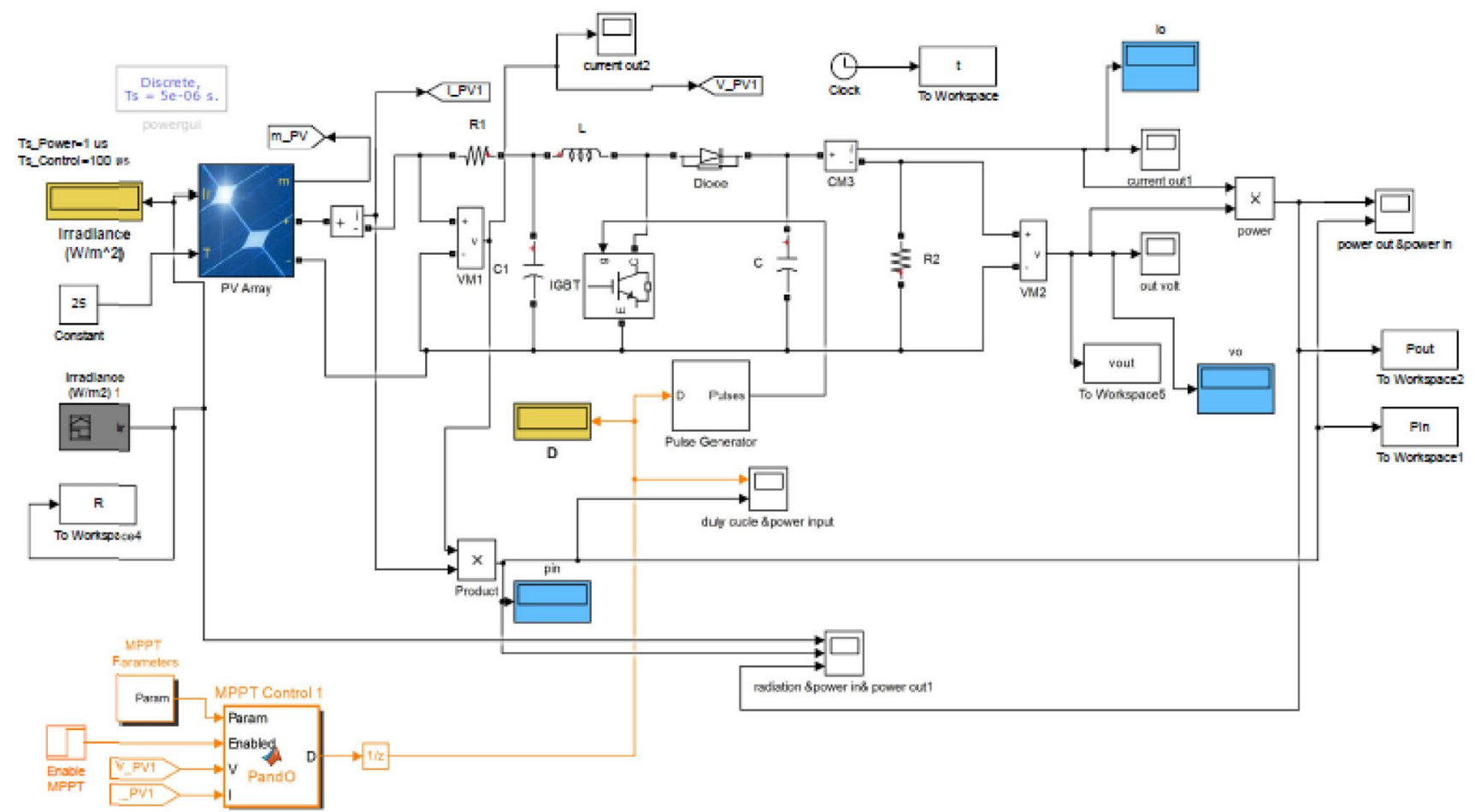

Fig. 24 The simulated model of PV system

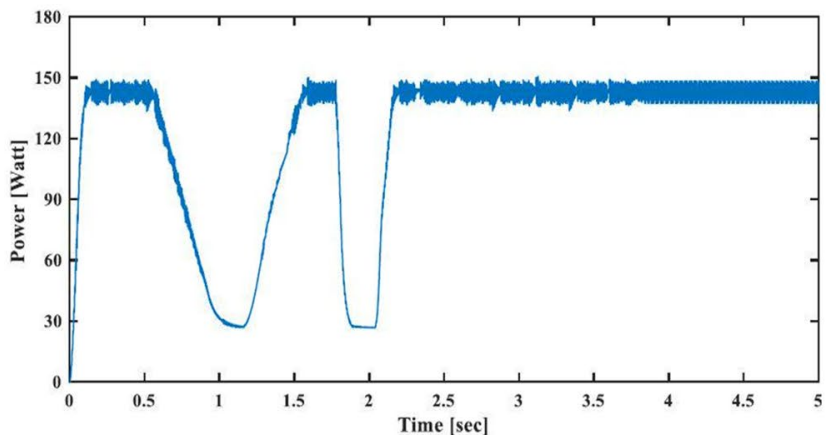

(a) The irradiation for many levels expressed in $\mathrm{W} / \mathrm{m}^{2}$

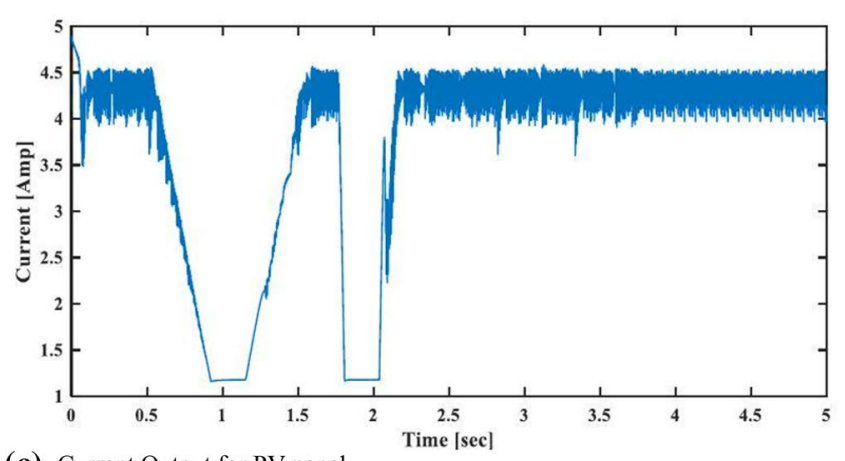

(c) Current Output for PV panel

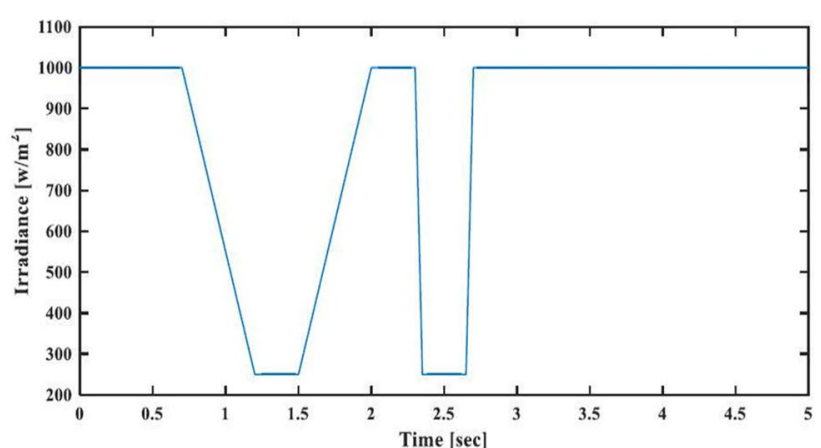

(b) Output power for the PV array

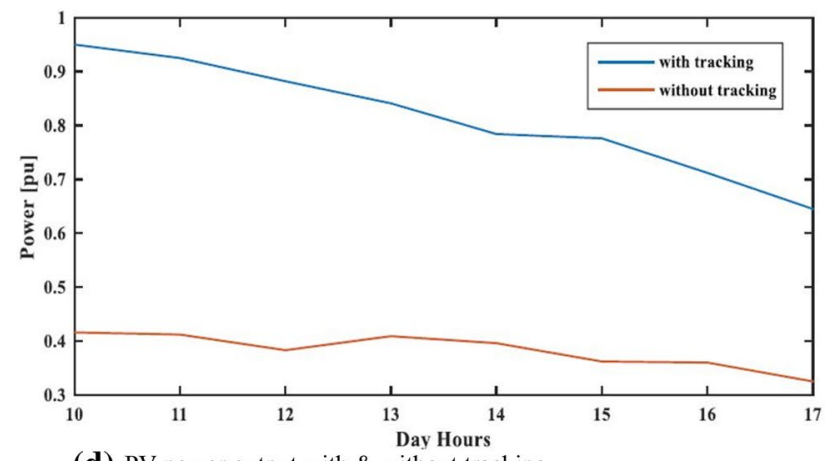

(d) PV power output with \& without tracking

Fig. 25 Performance of PV system

\section{SN Applied Sciences}


Inertia constant: $0.01197 \mathrm{~kg} \mathrm{~m}^{2}$, Fraction factor: $0.0012 \mathrm{~N} \mathrm{~m} \mathrm{~s}$

\section{Case Study (1): simulation results for PV system}

Figure 24 depicted the circuit model for the PV system based simulation. The present scenario investigates the system performance under variation of solar irradiance and PV array temperature is considered to be constant during the complete simulation time. The variation of solar irradiance is illustrated in Fig. 25a. The PV array output voltage is depicted in Fig. 25b. Figure $25 \mathrm{c}$ depicts the current output for the PV panel. The PV array operating power with and without tracking is illustrated in Fig. 25d.

Case Study (2): simulation results for wind turbine system

This part investigates the performance of wind system under variation of wind speed. Figure 26 depicted the circuit simulation model of the wind system. Figure $27 a$ shows wind speed and power coefficient using Matlab/ Simulation. Power and tip speed ratio is depicted in Fig. 27b. Figure 27c illustrates the simulation result of our generator actual and estimated speed value and Fig. 27d shows the average power. Finally Power versus speed with and without tracking is depicted in Fig. 27e.
Case Study (3): simulation result of hybrid system using multi-input rectifier topology

This part illustrates the modeling of a hybrid system based MATLAB/Simulink. A hybrid system will ensure that power supply can be preserve at an optimum level through cloudy days for a PV device and at low wind status for wind generators. Figure 28 show the complete system design for hybrid energy system based PV device and wind energy. Figure 29 illustrated the simulation results of the hybrid system performance.

\section{Conclusion}

This paper presents a detailed simulation of the PV/wind hybrid power system model. It is carried out under MATLAB/Simulink software. In this article, renewable energy resources are introduced like wind energy and solar system, the discussion presents a hybrid solar/wind systems to suppress the problems associated with both systems and using advantages aforementioned. The hybrid (PVwind) is investigated and implemented by using MATLAB program. The P\&O MPPT used for MPP tracking and illustrates the compassion between the generated power

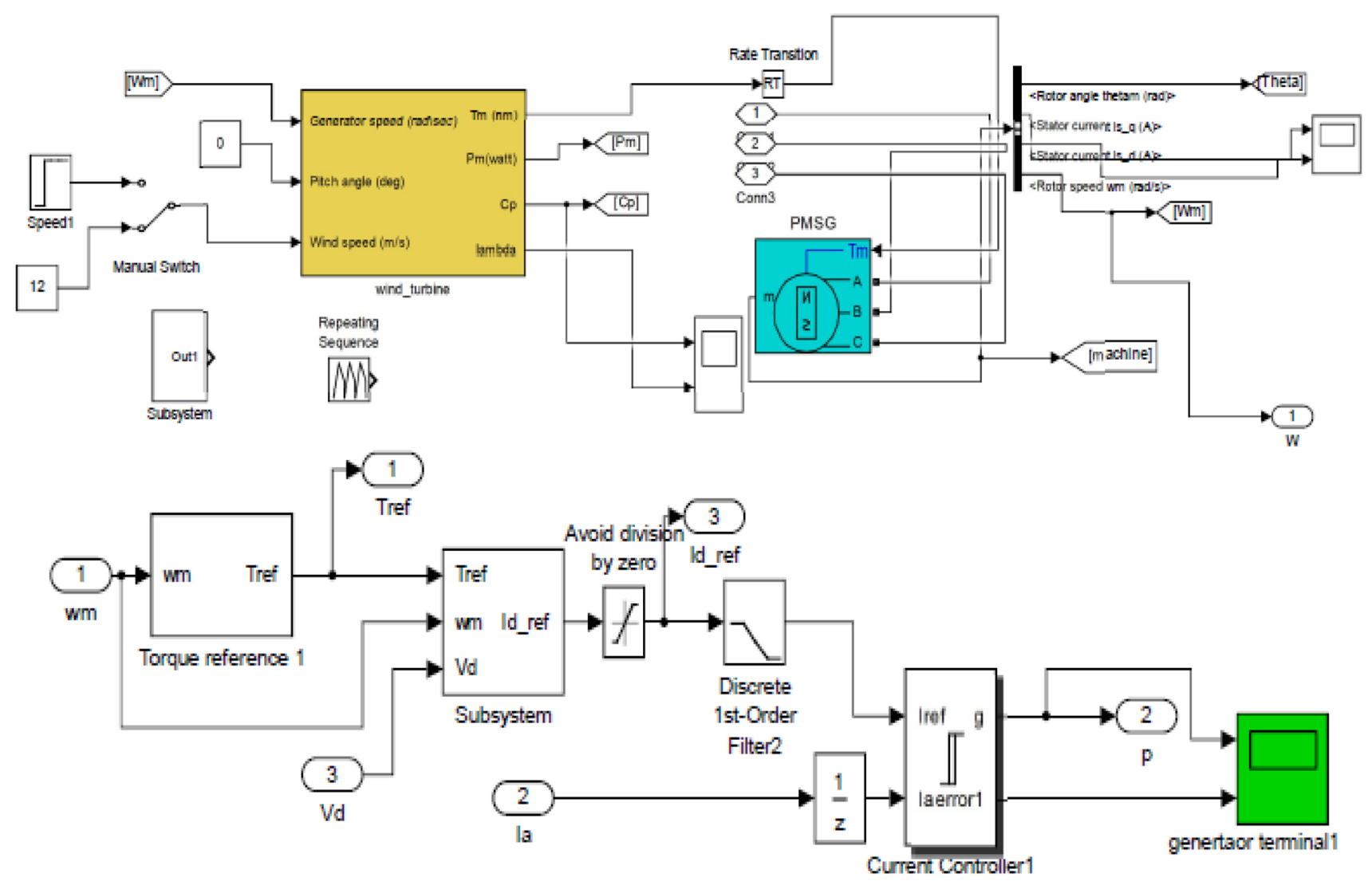

Fig. 26 The simulated model of WT system 

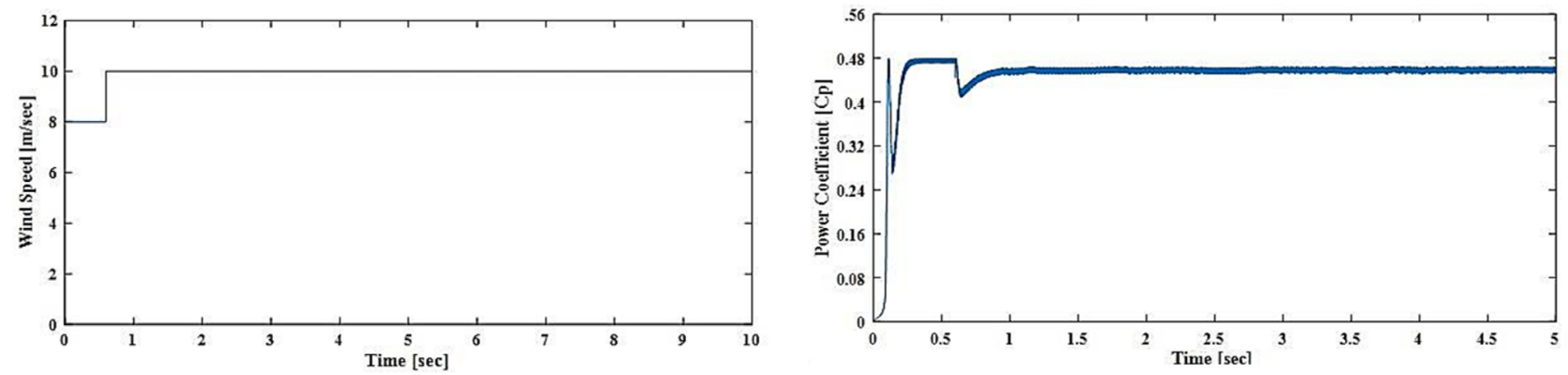

(a) Wind speed and Power coefficient using Matlab/Simulation
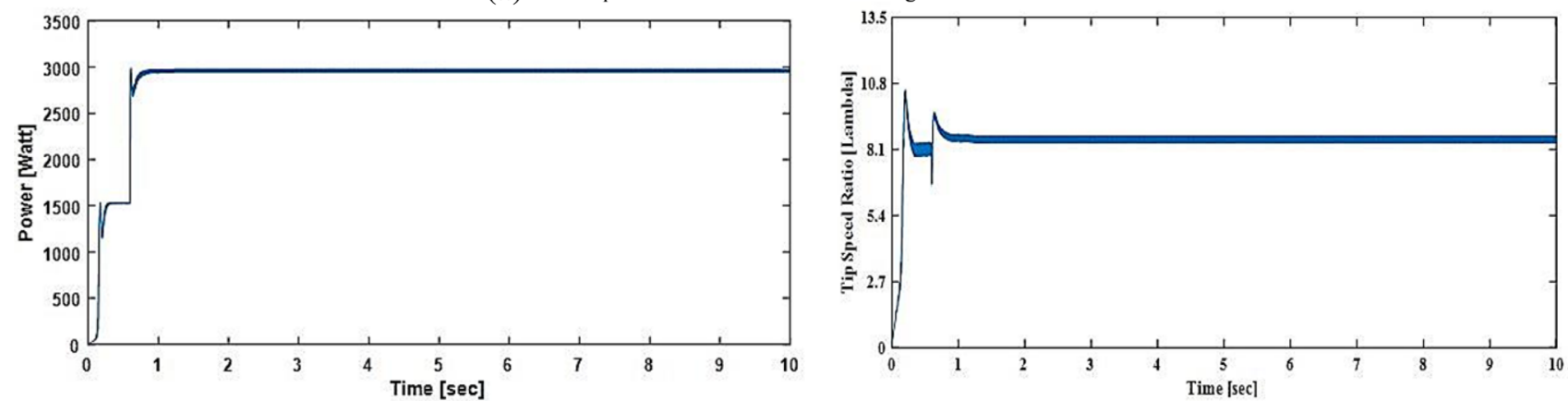

(b) Power and Tip speed ratio using Matlab/Simulation
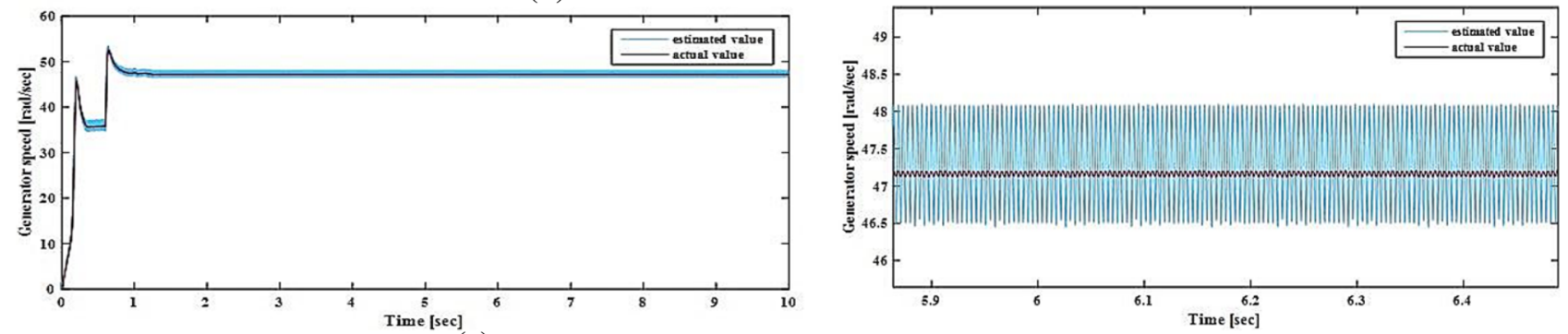

(c) Simulation result of our Generator actual and estimated speed value
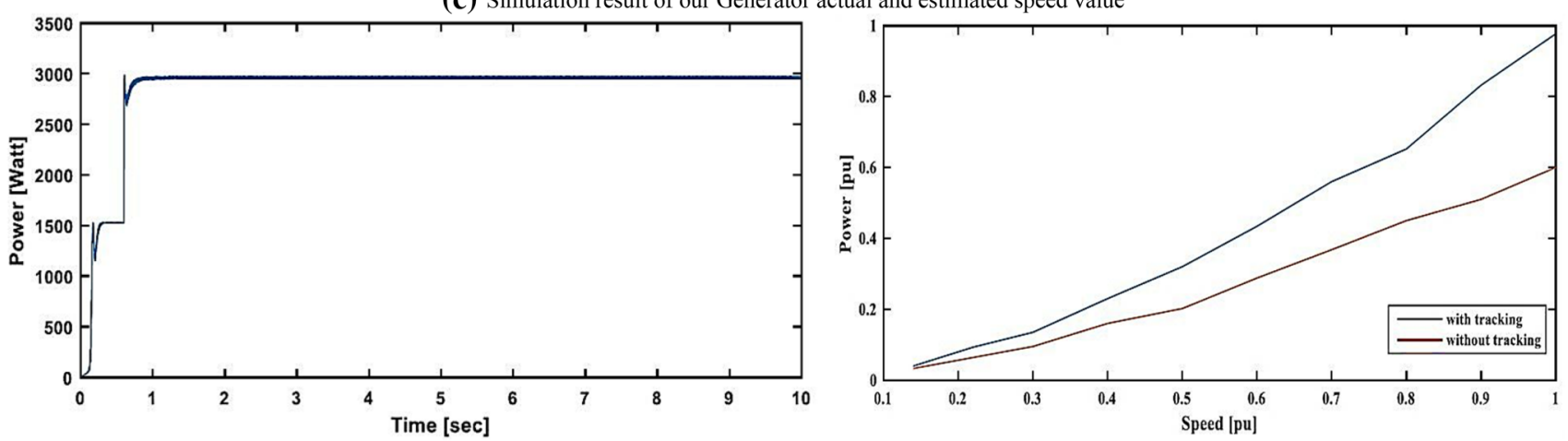

(d) Average power

(e) Power vs Speed with and without tracking

Fig. 27 Performance of wind system 
Fig. 28 Simulated model of the hybrid system
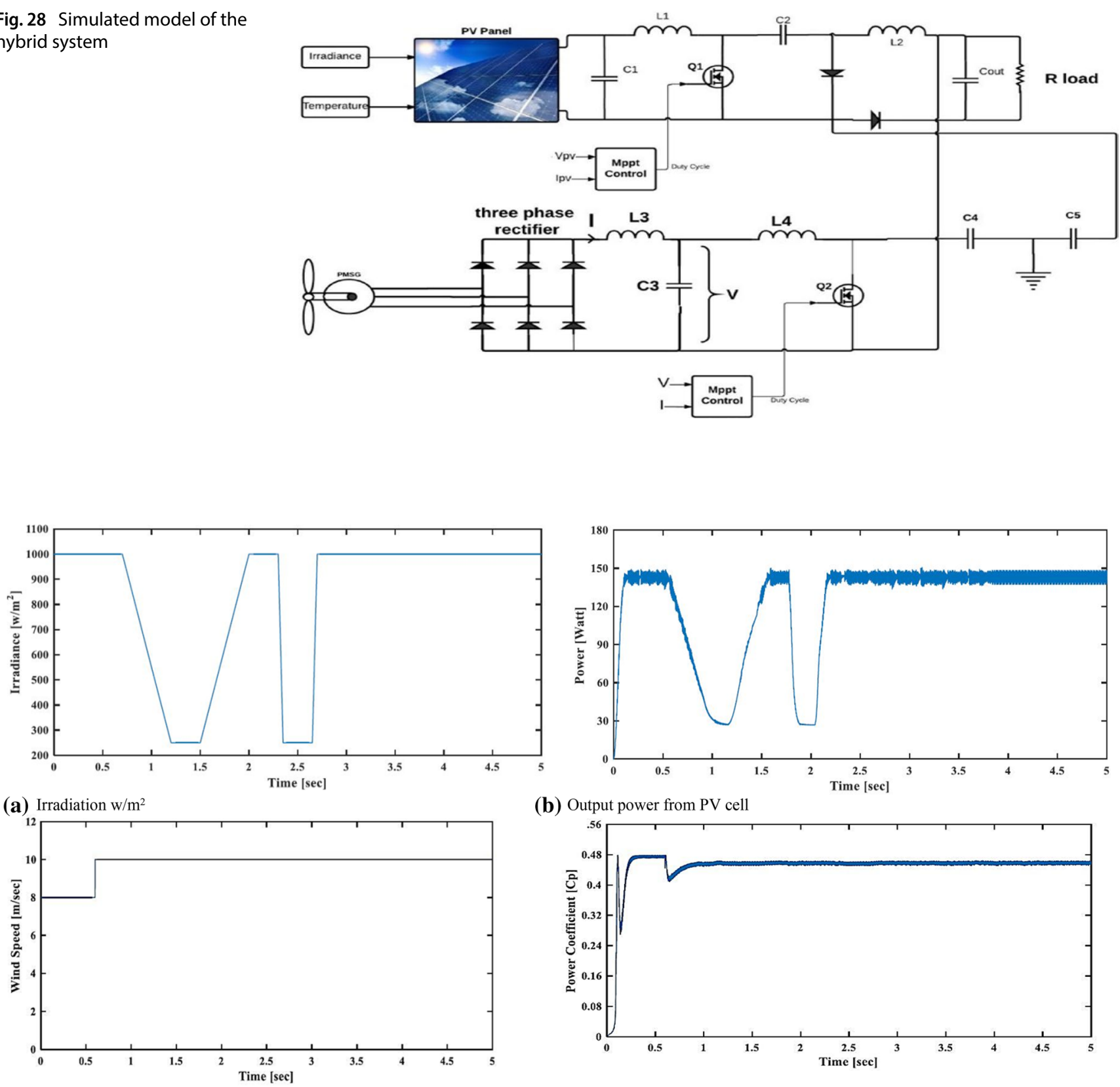

(b) Output power from PV cell

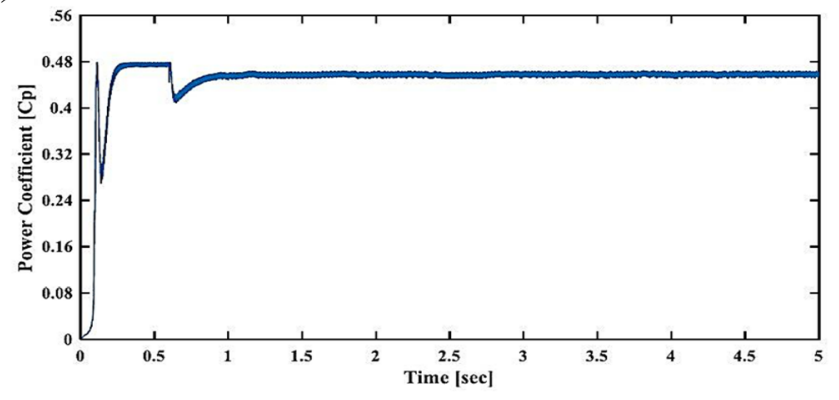

(c) Wind speed

(d) power coefficient

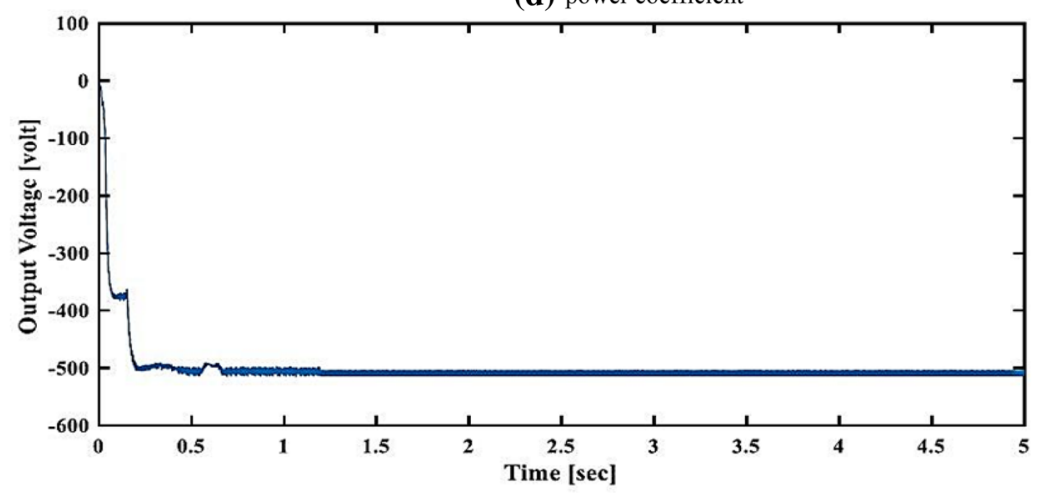

(e) Output Voltage from overall system

Fig. 29 Performance of hybrid system 
with and without the tracker. The numerical simulation results have proven the robustness of the proposed hybrid PV and wind energy in response to rapid changes in solar radiation and wind speed conditions.

\section{Compliance with ethical standards}

Conflict of interest Author wish to confirm that there are no known conflicts of interest associated with this publication and there has been no significant financial support for this work that could have influenced its outcome.

\section{References}

1. Kumar PV, Suresh A, Rashmi MR (2016) Optimal design of fused chopper based standalone hybrid wind solar system. Indian J Sci Technol 9(21):1-6

2. Abdullah MA, Yatim AHM, Tan CW, Saidur R (2012) A review of maximum power point tracking algorithms for wind energy systems. J Renew Sustain Energy Rev 16(2012):3220-3227

3. Rezvani A et al (2015) Enhancement of hybrid dynamic performance using ANFIS for fast varying solar radiation and fuzzy logic controller in high speeds wind. JES 11(1):11-26

4. Singaravel MR, Daniel SA (2015) MPPT with single DC-DC converter and inverter for grid connected hybrid wind-driven PMSG-PV system. IEEE Trans Ind Electron 62(8):1-8

5. Mohamed SA, El Sattar MA (2019) A comparative study of P\&O and INC maximum power point tracking techniques for gridconnected PV systems. SN Appl Sci J 1(174):1-13

6. Pillai V, Antony N (2015) Integrated multi input CUK converter used standalone system for WECS and PV. Int J Res Adv Technol 3(9):75-85

7. Saravanan K, Kumar AS, Nandini N (2016) Design and simulation of hybrid renewable energy system (HRES) to supply three phase induction motor using fuzzy logic controller. JCPS 9(4):1922-1929

8. Mohamed SA (2018) Design, control and performance analysis of a grid-connected hybrid system. Egypt Int J Eng Sci Technol 24:18-26

9. Verma D, Nema S, Shandilya AM, Dash SK (2015) Comprehensive analysis of maximum power point tracking techniques in solar photovoltaic systems under uniform insolation and partial shaded condition. J Renew Sustain Energy Rev 7:1-27

10. Bhasme S, Revankar AP (2012) Modeling and analysis of single phase grid connected photovoltaic system. Int J Power Syst Oper Energy Manag 1(4):52-58
11. Habbati B, Ramdani Y, Moulay F (2014) A detailed modeling of photovoltaic module using Matlab. NRIAG J Astron Geophys 3(1):53-61

12. Abdulateef J (2014) Simulation of solar off- grid photovoltaic system for residential unit. Int J Sustain Green Energy 4(3-1):29-33

13. Sera D, Mathe $L$, Kerekes $T$ (2013) On the perturb-and-observe and incremental conductance MPPT methods for PV systems. IEEE J Photovolt 3(3):1070-1078

14. Nemsi S, Barazane L, Diaf S, Malek A (2013) Comparative study between two maximum power point tracking (MPPT) techniques for photovoltaic system. Revue des Energies Renouvelables 16(4):773-782

15. Roberto F, Sonia L (2008) Energy comparison of MPPT techniques for PV Systems. WSEAS Trans Power Syst 3(6):446-455

16. Saleh EB, Matthew A, Volker $P$ (2014) Overview of maximum power point tracking control methods for PV systems. J Power Energy Eng 2:59-72

17. Carrillo C, Diaz-Dorado E, Silva-Ucha M, Perez-Sabín F (2010) Effects of WECS settings and PMSG parameters in the performance of a small wind energy generator. In: IEEE international symposium on power electronics, electrical drives, automation and motion, pp 766-771

18. Babu NR, Arulmozhivarman $P$ (2013) Wind energy conversion systems-a technical review. J Eng Sci Technol 8(4):493-507

19. Smida MB, Sakly A (2015) Pitch angle control for variable speed wind turbines. RESD 1:81-88

20. Lalouni S, Rekioua D, Idjdarene K, Tounzi AM (2014) An improved MPPT algorithm for wind energy conversion system. JES 10(4):484-494

21. Sachan A, Gupta AK, Samuel P (2017) A review of MPPT algorithms employed in wind energy conversion systems. J Green Eng 6(4):385-402

22. Hussain J, Mishra MK (2016) Adaptive maximum power point tracking control algorithm for wind energy conversion systems. IEEE Trans Energy Convers 31(2):1-9

23. Kavitha N, Durgalakshmi K, Kishore B (2015) Modified converter topology for hybrid wind and PV systems. Int J Adv Res Electr Electron Instrum Eng 4(7):6702-6709

24. Sudharshan A, Yohan M, Shrujan RVK, Gayathri Y (2013) A hybrid wind-solar energy system using cuk-sepic fused converter. Int J Eng Res Appl 3(6):287-293

Publisher's Note Springer Nature remains neutral with regard to jurisdictional claims in published maps and institutional affiliations. 